\title{
Theoretical Modeling of the Doping Process in Polypyrrole by Calculating UV/Vis Absorption Spectra of Neutral and Charged Oligomers
}

\author{
Serife Okur and Ulrike Salzner* \\ Department of Chemistry, Bilkent University, Bilkent, 06800 Ankara, Turkey
}

Received: July 17, 2008; Revised Manuscript Received: September 9, 2008

\begin{abstract}
Changes in absorption spectra during doping of oligopyrroles were investigated with time-dependent density functional theory on optimized structures of neutral, singly, and doubly charged pyrrole oligomers with up to 24 rings. In the absence of counterions, defects are delocalized. Counterions induce localization. For dications two polarons on the same chain are preferred over a bipolaron. Intragap absorptions arise in charged species, no matter whether defects are localized or delocalized. Cations and dications give rise to two sub-band transitions. The cation peaks have lower energies than those of dications. The first excitations of cations have lower oscillator strengths than the second; for dications the second peak is weaker than the first. For very long oligomers, the second sub-band absorption vanishes and a third one appears at higher energy. The behavior of pyrrole oligomers is analogous to that of thiophene oligomers. Theoretical UV spectra for cations and dications of short oligomers (six to eight rings) match experimental spectra of polypyrrole at low and at high doping levels, respectively. The error in the theoretical calculations is about $0.4 \mathrm{eV}$, slightly larger than for thiophene oligomers at the same level of theory.
\end{abstract}

\section{Introduction}

The discovery of conducting organic polymers (COPs) dates back to 1963 when Weiss et al. ${ }^{1-3}$ observed that pyrolysis of tetraiodopyrrole produced polypyrrole (PPy) that conducted electricity depending on its iodine content. The material consisted of infusible, insoluble, amorphous polymers, and the conductivity was relatively low. Research on COPs intensified when polyacetylene (PA) films were shown to increase their conductivity by 11 orders of magnitude upon doping with iodine, bromine, chlorine, and arsenic pentafluoride. ${ }^{4,5} \mathrm{PA}$ remains of high interest for research, but for applications heterocyclic COPs such as PPy, polythiophene (PTh), and poly(ethylenedioxythiophene (PEDOT) are more interesting because they are chemically more stable. ${ }^{6-8}$

PPy and PTh have many similarities. Both are aromatic in the ground state and tend to become quinoid upon doping with electron acceptors (p-doping). ${ }^{9}$ Both achieve similar conductivities at $\sim 10^{3} \mathrm{~S} / \mathrm{cm}^{10}{ }^{10} \mathrm{p}$-Doping is associated with comparable changes in the absorption spectra of both polymers. The strong $\pi-\pi^{*}$ transitions of the neutral species decrease in intensity and new sub-band transitions develop. ${ }^{11}$ Despite the similarities, there are differences between PPy and PTh. The band gap of PPy is about $0.4 \mathrm{eV}$ larger than that of PTh, and PPy has a lower oxidation potential. ${ }^{6}$ As a result, PPy is usually obtained in partially doped form and needs to be reduced for investigation of properties of pristine PPy. ${ }^{12}$ Upon reduction, two $^{13}$ or three ${ }^{12,14}$ features develop at very low doping levels, while PTh always shows two. ${ }^{15}$ There is a considerable variation, however, in the experimental data on PPy doping. ${ }^{12,13,16-18}$

The sub-band transitions of doped COPs were rationalized originally in terms of bipolaron formation since there is no correlation between ESR signals and conductivity. ${ }^{9,19-22}$ Preference for bipolarons has been questioned by some experimentalists from the start, ${ }^{17,18,23-26}$ but others rationalized their observations in terms of bipolarons. ${ }^{13,16,22}$ Especially after the doping

\footnotetext{
* Corresponding author. E-mail: salzner@fen.bilkent.edu.tr.
}

behavior of monodisperse polyenes ${ }^{27-29}$ and oligothiophenes $(\mathrm{OTs})^{30-41}$ was investigated in solution, the bipolaron model was challenged. Unfortunately, many fewer experimental data are available for well-defined pyrrole oligomers (OPs). ${ }^{42-48} \mathrm{We}$ are presently aware of only one investigation reporting UV data of a charged pyrrole oligomer of known chain length, pentapyrrole (5P) cation and dication. ${ }^{47}$ In addition, several studies were done on substituted OPs. ${ }^{49-51}$ In the oligomer studies the issue of bipolaron formation was not addressed and the interpretation of polymer results remains controversial. $8,12,13,16,17,20,22,23,25,52-55$

Electronic structures of PPy and OPs have been investigated theoretically before; ${ }^{20,56-70}$ however, we are not aware of calculations of absorption spectra during the doping process of pyrrole oligomers or polymers. We have recently calculated such spectra for polyenes ${ }^{71}$ and OTs. ${ }^{72}$ During these investigations an appropriate level of theory was established by comparison with available experimental and high-level theoretical data. It was shown that accurate excitation energies can be obtained for neutral oligomers with time-dependent Hartee-Fock (TDHF) theory and for cations and anions with time-dependent density functional theory (TDDFT). Here we are applying the same methods for investigation of the doping-induced changes in excitation spectra of OPs and we are comparing the results with those previously obtained for OTs. Although all theoretical absorption energies tend to be too high for pyrrole oligomers, on combining theoretical and experimental information a relatively clear interpretation of the doping process emerges.

\section{Methods}

Pyrrole oligomers with $2-24$ pyrrole rings $(2 \mathrm{P}-24 \mathrm{P})$ were optimized in neutral form, with $2-19$ rings as cations $\left(2 \mathrm{P}^{+}-19 \mathrm{P}^{+}\right)$and with $2-16$ rings as dications $\left(2 \mathrm{P}^{2+}-16 \mathrm{P}^{2+}\right)$. Dications were treated as closed-shell and open-shell species (singlet biradicals). Geometry optimizations were done with density functional theory employing the B3P86 hybrid func- 
tional $^{39,40}$ with $30 \%$ HF exchange ${ }^{41}$ (B3P86-30\%) and StevensBasch-Krauss pseudopotentials with polarized split-valence basis sets (CEP-31G*). ${ }^{73}$ For neutral $2 \mathrm{P}$ and $4 \mathrm{P}$ the effect of twisting was examined. All charged oligomers were kept planar $\left(C_{2 h}\right.$ symmetry for even numbers of rings and $C_{2 v}$ symmetry for odd numbers of rings). A frequency calculation on $6 \mathrm{P}^{+}$ confirmed that the planar form is a minimum on the potential energy surface.

Excited states of neutral species were obtained at the timedependent Hartree-Fock (TDHF/CEP-31G*) and TDB3P86$30 \%$ CEP-31G* levels. Charged species were treated with TDB3P86-30\% CEP-31G*. Switching the methods is necessary because TDDFT methods underestimate excitation energies of long conjugated $\pi$-systems. ${ }^{74-79}$ In contrast, TDHF is very accurate for excitation energies of neutral $\pi$-systems, ${ }^{71,72,80}$ but fails for open-shell systems because of spin contamination..$^{71,72}$ Interestingly, TDDFT does not underestimate excitation energies of charged $\pi$-systems and does not suffer from spin contamination for OTs even with hybrid functionals. ${ }^{71,72,81-83}$ It seems that the spin-contamination problem gets smaller with increasing HOMO-LUMO gap. While polyenes suffer from spin contamination at the B3P86-30\% level, the expectation values of the spin operator are 0.76 for $25 \mathrm{~T}^{+}$and 0.84 for $19 \mathrm{~T}-\mathrm{Cl}_{3}$. Spin contamination is even less for OPs with values of 0.76 for $20 \mathrm{P}^{+}$ and 0.77 for $19 \mathrm{P}-\mathrm{Cl}_{3}$. Thus all species treated here have expectation values of the spin operator that are very close to the exact one of 0.75 . Test calculations with $6-31+\mathrm{G}^{* 84}$ and CC-PVQZ ${ }^{85}$ basis sets were carried out for 2P. Vertical excitation energies without optimizing the geometries of the excited states were used as estimates of experimental $\varepsilon_{\max }$ values. As discussed recently, ${ }^{83}$ the error caused by neglecting the vibrational structure of the bands is on the order of $0.2 \mathrm{eV}$ and is therefore smaller than the inherent errors of the TDB3P8630\%/CEP-31G* approach.

The influence of counterions was probed with $\mathrm{Cl}_{3}{ }^{-}$as a model for iodine doping. An earlier study ${ }^{63}$ employed $\mathrm{Cl}$ anions, but the proximity of $\mathrm{Cl}^{-}$to the backbone and the small charge transfer suggest that there was covalent bonding between counterion and backbone. $7 \mathrm{P}-\mathrm{Cl}_{3}, 9 \mathrm{P}-\mathrm{Cl}_{3}, 11 \mathrm{P}-\mathrm{Cl}_{3}, 13 \mathrm{P}-\mathrm{Cl}_{3}$, and 19P- $\mathrm{Cl}_{3}$ complexes were fully optimized. $\mathrm{Cl}_{3}{ }^{-}$counterions, in contrast to $\mathrm{Cl}^{-}, 63$ prefer to lie in the plane of the backbone. Test calculations on $7 \mathrm{P}$ revealed that $\mathrm{Cl}_{3}{ }^{-}$can bridge two hydrogen atoms bonded to the carbon atoms like with thiophene oligomers or it can lie close to the hydrogen bonded to nitrogen. Attachment to the $\mathrm{N}-\mathrm{H}$ bond is lower in energy, but absorption spectra of both structures differ very little. Therefore, the structures that resemble those of thiophene oligomers were used. Solvent effects were included with the polarized continuum model (PCM) ${ }^{86}$ using dichloromethane as solvent. All calculations were carried out with Gaussian 03. ${ }^{87}$

\section{Results}

Neutral Oligomers. Bond lengths in the inner rings of oligomers converge rapidly with increasing chain length and reach converged values at the third ring from the chain end for long enough oligomers. The inner rings of pyrrole oligomers have the following parameters: $\mathrm{C}-\mathrm{C}, 1.429 \AA$; $\mathrm{C}=\mathrm{C}, 1.402 \AA$; $\mathrm{C}-\mathrm{N}, 1.380 \AA$; inter-ring single bond, $1.458 \AA$. This leads to a bond length alternation of $0.056 \AA$. These parameters are in essential agreement with B3LYP/6-31G* results by Millefiori et al. ${ }^{64}$ The only difference is that the pseudopotential basis set leads to slightly longer bonds. The geometry of pyrrole rings is very similar to that of thiophene rings in oligothiophenes, which

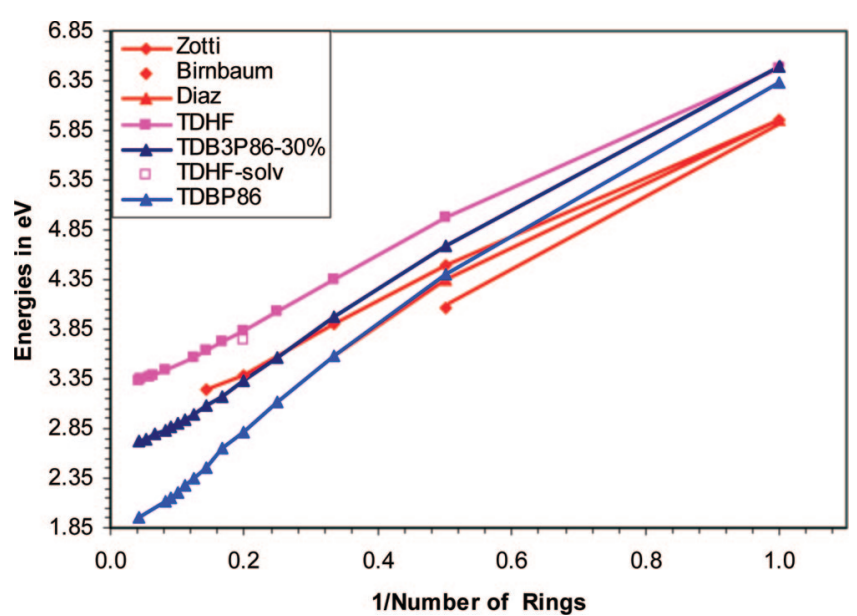

Figure 1. Theoretical and experimental excitation energies of neutral pyrrole oligomers.

TABLE 1: Excitation Energies (in eV) of Planar Pyrrole Oligomers in the Gas Phase at TDHF/CEP-31G*, TDB3P86-30/CEP-31G*, and TDBP86/CEP-31G* Compared to Experimental $\varepsilon_{\max }$ Values in Solution

\begin{tabular}{cllll}
\hline $\begin{array}{c}\text { no. of } \\
\text { rings }\end{array}$ & \multicolumn{1}{c}{ TDHF } & TDB3P86-30\% & TDBP86 & \multicolumn{1}{c}{ expt } \\
\hline 1 & 6.47 & 6.49 & 6.34 & $5.96^{47} / 5.96^{52}$ \\
2 & $4.97 /$ & 4.69 & 4.41 & $4.49^{47} / 4.35^{52} / 4.06^{48}$ \\
& 4.84 (solvent) & & & \\
3 & 4.35 & 3.97 & 3.58 & $3.91^{47} / 3.59^{52}$ \\
4 & $4.03 /$ & $3.57 /$ & 3.11 & $3.54^{45}$ \\
& 4.11 (nonplanar) & 3.63 (nonplanar) & & \\
5 & $3.84 /$ & 3.34 & 2.81 & $3.38^{47}$ \\
& 3.74 (solvent) & & & \\
6 & 3.72 & 3.18 & 2.60 & $3.25^{47}$ \\
7 & 3.63 & 3.08 & 2.46 & \\
8 & 3.57 & 3.00 & 2.35 & \\
9 & & 2.94 & 2.27 & \\
10 & & 2.90 & 2.21 & \\
11 & & 2.87 & 2.16 & \\
12 & 3.44 & 2.84 & 2.12 & \\
15 & & 2.79 & & \\
16 & 3.39 & & & \\
18 & 3.37 & & & \\
19 & & 2.75 & & \\
22 & 3.35 & $2.72 / 3.01^{a}$ & & \\
24 & 3.34 & & &
\end{tabular}

${ }^{a}$ At the BP86 level some of the peaks split into several close-lying features. This is probably caused by the fact that energy levels get very close with pure DFT for long oligomers.

have practically the same $\mathrm{C}-\mathrm{C}$ bond lengths (1.427 and 1.458 $\AA$ ) and only slightly shorter $\mathrm{C}=\mathrm{C}$ bonds of $1.396 \AA$.

TDHF, TDB3P86-30\%, and TDBP86 excitation energies of planar pyrrole oligomers in the gas phase based on B3P86-30\% geometries are compared with Zotti et al.' ${ }^{47}$ and Diaz et al.' ${ }^{42}$ solution data in Figure 1 and in Table 1. For bithiophene the matrix value of Birnbaum and Kohler ${ }^{48}$ is also included. All experiments agree on the pyrrole monomer, but differences emerge with increasing chain length. For $2 \mathrm{P}$ the matrix value is lowest. Diaz et al. ${ }^{42}$ obtained a lower value in liquid solution than Zotti et al. ${ }^{47}$ The gap between the experimental results widens for 3P. TDHF excitation energies overestimate experimental results. TDDFT agrees better with experimental data, but Figure 1 shows that this is due to a too-fast decrease with increasing chain length. A detailed comparison between theory and experiment is given in the Discussion.

Cations. Cations were optimized in the absence and in the presence of a $\mathrm{Cl}_{3}{ }^{-}$counterion. The $\mathrm{Cl}_{3}{ }^{-}$counterion prefers to be placed in the plane of the backbone rather than above. As mentioned in Methods, there is a second structure with $\mathrm{Cl}_{3}{ }^{-}$ 


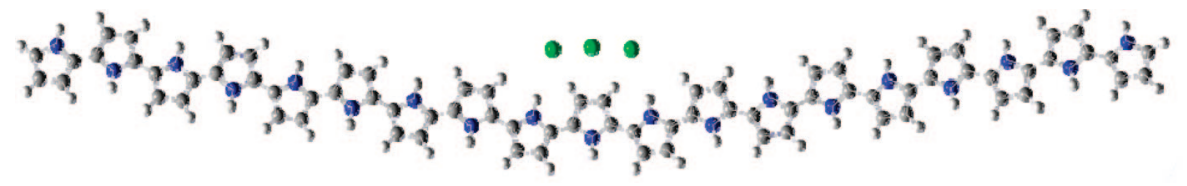

Figure 2. Optimized structure of $19 \mathrm{P}-\mathrm{Cl}_{3}$.

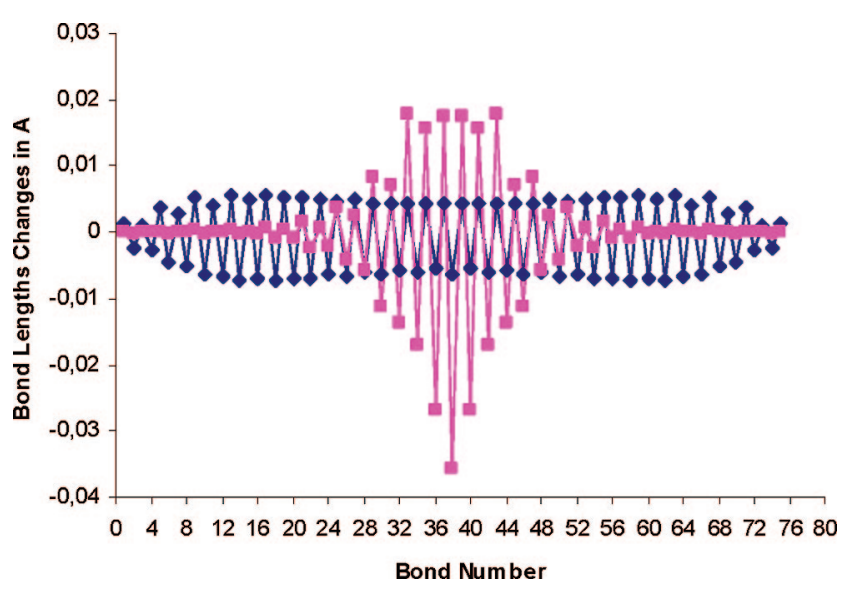

Figure 3. Bond length changes in $19 \mathrm{P}^{+}$(blue diamonds) and $19 \mathrm{P}-\mathrm{Cl}_{3}$ (pink squares) compared to neutral 19P.

lying on the opposite side of the chain close to the $\mathrm{N}-\mathrm{H}$ hydrogen. Since spectra are almost identical with both counterion positions, only one structural alternative was pursued. The optimized structure of $19 \mathrm{P}-\mathrm{Cl}_{3}$ is shown in Figure 2. Bond length changes with respect to the neutral form are plotted for $19 \mathrm{P}^{+}$and $19 \mathrm{P}-\mathrm{Cl}_{3}$ in Figure 3.

In the bare cation the geometry distortion is delocalized over the entire chain. $\mathrm{C}-\mathrm{C}$ single bonds shorten by about $0.006 \AA$ and $\mathrm{C}-\mathrm{C}$ double bonds lengthen by about $0.004 \AA$. In the presence of a counterion, there is no geometry change in the first four rings from each terminal compared to the neutral system (Figure 3 ). Hence the total defect width is 11 rings. The central three rings are quinoid, and the distortion decreases exponentially with distance from the counterion.

The geometry difference induced by the counterion is substantial. To assess the energetic effect associated with this geometry change, the counterion was removed from the complex and a single point energy calculation was performed on the bare cation having the geometry of the complex $\left(19 \mathrm{P}^{+} / / 19 \mathrm{P}-\mathrm{Cl}_{3}\right)$. The energy difference between the optimized cation $19 \mathrm{P}^{+}$and $19 \mathrm{P}^{+} / / 19 \mathrm{P}-\mathrm{Cl}_{3}$ is $3.78 \mathrm{kcal} / \mathrm{mol}, 0.20 \mathrm{kcal} / \mathrm{mol}$ per ring.

In Figure 4, the charge distributions in $19 \mathrm{P}^{+}, 19 \mathrm{P}-\mathrm{Cl}_{3}$, and $19 \mathrm{P}^{+} / / 19 \mathrm{P}-\mathrm{Cl}_{3}$ are plotted. In the bare cation the charge is distributed over the entire molecule. The charge on $\mathrm{Cl}_{3}{ }^{-}$in 19P$\mathrm{Cl}_{3}$ is $-0.94 \mathrm{e}$. Thus, the charge transfer is almost complete. A sharp peak of positive charge is obtained at the central ring close to the counterion. The positive charge decreases rapidly over the next four rings, so that the charge is spread over nine rings. In $19 \mathrm{P}^{+} / / 19 \mathrm{P}-\mathrm{Cl}_{3}$ the positive charge is delocalized although the geometry is the same as that of $19 \mathrm{P}-\mathrm{Cl}_{3}$. Therefore, the presence of a counterion leads to defect localization; geometry distortion alone does not.

TDB3P86-30\%/CEP-31G* excitation energies for $2 \mathrm{P}^{+}$through $19 \mathrm{P}^{+}$are listed in Table 2. Excited states are characterized using Pariser's ${ }^{88}$ notation as shown in Scheme 1. Weak features with oscillator strengths below 0.25 are omitted. Stick spectra are plotted in Figures 5 and 6 . The developments of energies and oscillator strengths with increasing oligomer size are plotted in Figures 7 and 8.

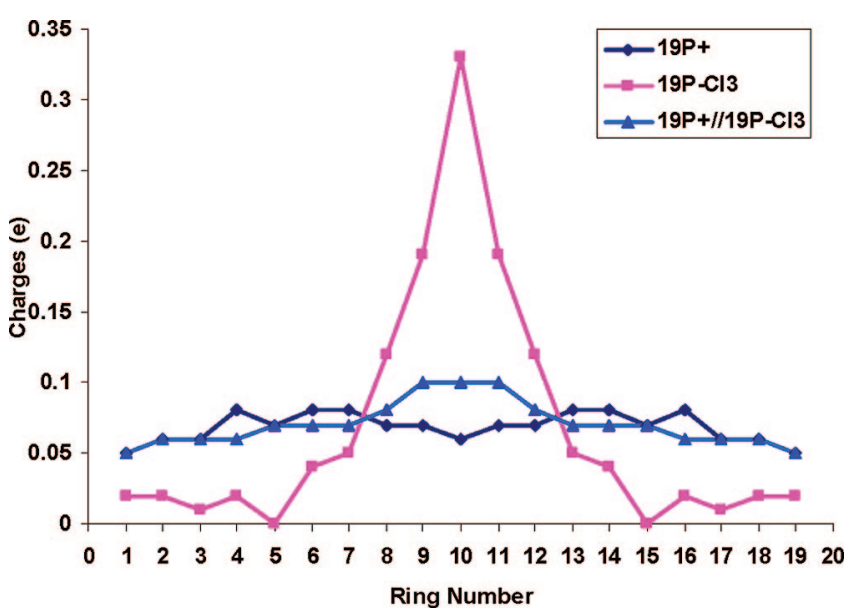

Figure 4. Distribution of the positive charge in $19 \mathrm{P}^{+}, 19 \mathrm{P}-\mathrm{Cl}_{3}$, and $19 \mathrm{P}^{+} / / 19 \mathrm{P}-\mathrm{Cl}_{3}$.

There is one strong sub-band absorption for $2 \mathrm{P}^{+}$, which arises from a $1-1^{\prime}$ transition (radical cation in Scheme 1). $3 \mathrm{P}^{+}$through $5 \mathrm{P}^{+}$are predicted to have two peaks. E1 (the lower energy peak) is dominated by a $2-1$ transtion, and E2 (the higher energy peak) is dominated by a $1-1^{\prime}$ transition. E2 splits into two features for $4 \mathrm{P}^{+}$, but the resulting peaks lie very close and the splitting vanishes for $5 \mathrm{P}^{+}$. Similar peak splitting is predicted at TDDFT $^{72}$ and CASPT2 ${ }^{89}$ for terthiophene. For $6 \mathrm{P}^{+}$and all longer oligomers, E2 splits into two components and three or four sub-band peaks are predicted for longer oligomers.

Figures 7 and 8 show that the oscillator strength of E1 increases at first and becomes almost constant at about $12 \mathrm{P}^{+}$. The oscillator strength of E2 levels off at $7 \mathrm{P}^{+}$and decreases for longer oligomers. E2 and E3 of medium-long and long oligomers arise from the $1-1^{\prime}$ transition, which combines with $3-1^{\prime}$ and $2-2^{\prime}$ transitions. As a result, E3 gains importance at the expense of E2 with increasing chain length. E3 becomes the dominant peak at $11 \mathrm{P}^{+}$. E4 decreases and increases in strength as the oligomers get longer but does not develop into a major feature.

The nature of the electronic states of medium sized-oligomers is illustrated for $13 \mathrm{P}^{+}$in Figure 9. The molecular orbitals involved in the transitions are plotted in Figure 10. Only E1 is dominated by a single electronic transition. E2 and E3 are multiconfigurational, arising from similar electronic transitions with different signs and weights. E1 can be considered to be a transition from the valence band into the empty polaron level $(2-1$ transition). Figure 10 shows that the electron moves from a level that has the largest electron density at the chain ends to a level with electron density distributed evenly over all but the terminal rings. E2 and E3 are related to band transitions of the neutral form $\left(1-1^{\prime}\right)$. The 1-level (HOMO of the neutral species) looks very similar for $\alpha$ - and $\beta$-parts of the wave function and resembles the delocalized HOMO of neutral pyrrole oligomers. In contrast, $1^{\prime}$ has the largest electron density in the middle of the molecule. Therefore, the $1-1^{\prime}$ transition moves electron density toward the center of the molecule. The energy difference between the 1 and $1^{\prime}$ energy levels is smaller than in the neutral oligomer. E1 and E2 $(0.38 \mathrm{eV}+2.02 \mathrm{eV}=2.40 \mathrm{eV})$ do not 
TABLE 2: TDB3P86-30\%/CEP-31G* Excitation Energies (in eV) of Pyrrole Cations and Oscillator Strengths (in Parentheses) ${ }^{a}$

\begin{tabular}{|c|c|c|c|c|c|c|}
\hline & E1 & E2 & E3 & E4 & E5 & E6 \\
\hline $2 \mathrm{P}^{+}$ & $3.87(0.54)$ & & & & & \\
\hline $3 \mathrm{P}^{+}$ & $1.83(0.24)$ & $3.19(0.70)$ & & & & \\
\hline $4 \mathrm{P}^{+}$ & $1.44(0.42)$ & $2.67(0.61)$ & $2.82(0.31)$ & & & \\
\hline $6 \mathrm{P}^{+}$ & $0.98(0.81)$ & $2.36(1.16)$ & & & & \\
\hline $7 \mathrm{P}^{+}$ & $0.82(0.98)$ & $2.27(1.06)$ & $3.50(0.41)$ & & & \\
\hline $7 \mathrm{P}-\mathrm{Cl}_{3}(\mathrm{~N}-\mathrm{H}$ bonded $)$ & $1.10(0.87)$ & $2.35(0.92)$ & not calcd & & & \\
\hline $9 \mathrm{P}^{+}$ & $0.61(1.23)$ & $2.13(0.95)$ & $3.07(0.50)$ & $3.16(0.47)$ & & \\
\hline $9 \mathrm{P}-\mathrm{Cl}_{3}$ & $0.89(1.09)$ & $2.19(0.91)$ & $2.48(0.57)$ & not calcd & & \\
\hline $10 \mathrm{P}^{+}$ & $0.53(1.31)$ & $2.10(0.84)$ & $2.97(0.82)$ & $3.00(0.49)$ & & \\
\hline $11 \mathrm{P}^{+}$ & $0.47(1.36)$ & $2.06(0.73)$ & $2.90(1.83)$ & $3.26(0.30)$ & & \\
\hline $11 \mathrm{P}-\mathrm{Cl}_{3}$ & $0.81(1.24)$ & $2.10(0.63)$ & $2.34(1.00)$ & not calcd & & \\
\hline $12 \mathrm{P}^{+}$ & $0.42(1.39)$ & $2.04(0.62)$ & $2.85(2.40)$ & not calcd & & \\
\hline $16 \mathrm{P}^{+}$ & $0.29(1.43)$ & $1.97(0.39)$ & $2.74(4.41)$ & $3.29(0.32)$ & & \\
\hline $19 \mathrm{P}^{+}$ & $0.23(1.42)$ & $1.94(0.29)$ & not calcd & & & \\
\hline $19 \mathrm{P}-\mathrm{Cl}_{3}$ & $0.65(1.08)$ & $0.96(0.41)$ & $2.12(0.72)$ & $2.28(1.14)$ & $2.47(0.30)$ & $2.84(0.69)$ \\
\hline
\end{tabular}

${ }^{a}$ Included are all transitions below the TDHF band gap of the neutral species with oscillator strengths above 0.25.

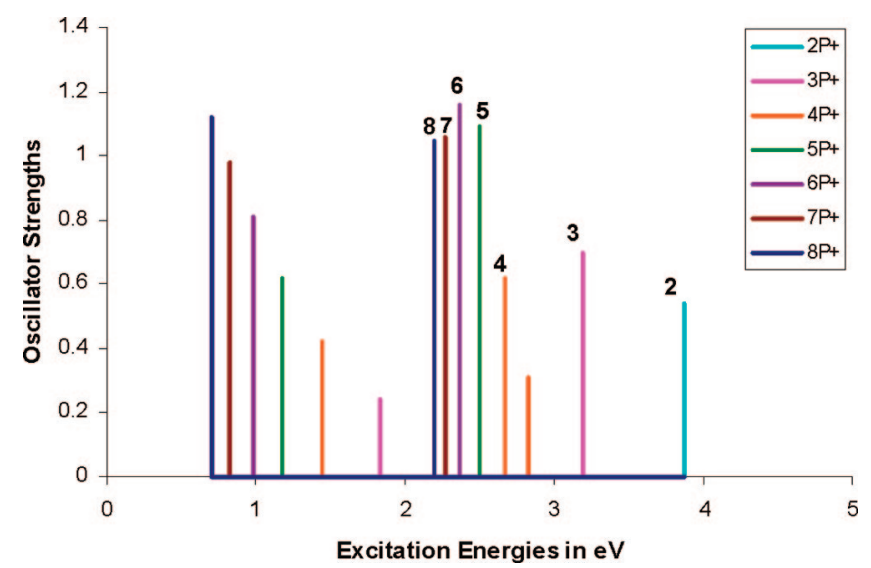

Figure 5. Stick spectra for $2 \mathrm{P}^{+}$through $8 \mathrm{P}^{+}$at the TDB3P86-30\% level.

\section{SCHEME 1}

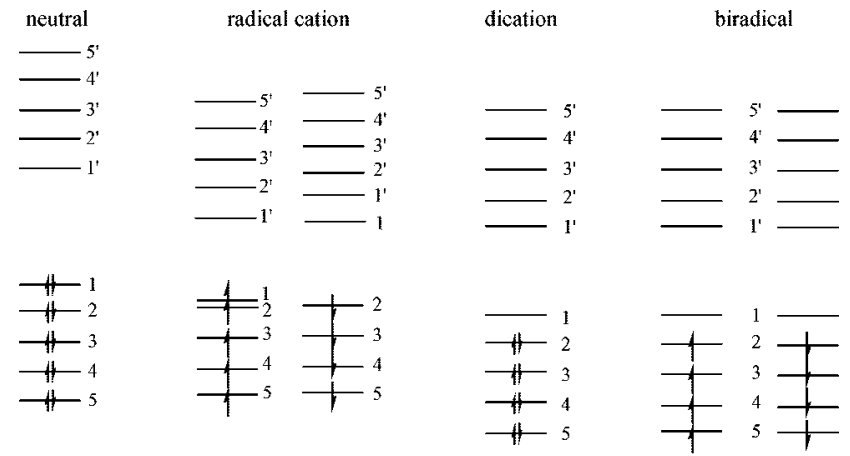

$\underset{1 \rightarrow 1^{*}}{\text { HOMO-LUMO }} \stackrel{2 \rightarrow 1}{1 \rightarrow 1} \quad \begin{gathered}\text { HOMO-LUMO } \\ 2 \rightarrow 1\end{gathered}$

add up to the excitation energy of the neutral analogue (3.42 $\mathrm{eV}$ (TDHF) or $2.82 \mathrm{eV}$ (TDB3P86-30\%)). This is in contrast to the results with tight binding methods. ${ }^{16,90}$

The effect of the counterions was investigated for $9 \mathrm{P}-\mathrm{Cl}_{3}$, $11 \mathrm{P}-\mathrm{Cl}_{3}, 13 \mathrm{P}-\mathrm{Cl}_{3}$, and $19 \mathrm{P}-\mathrm{Cl}_{3}$. Data are included in Table 2.

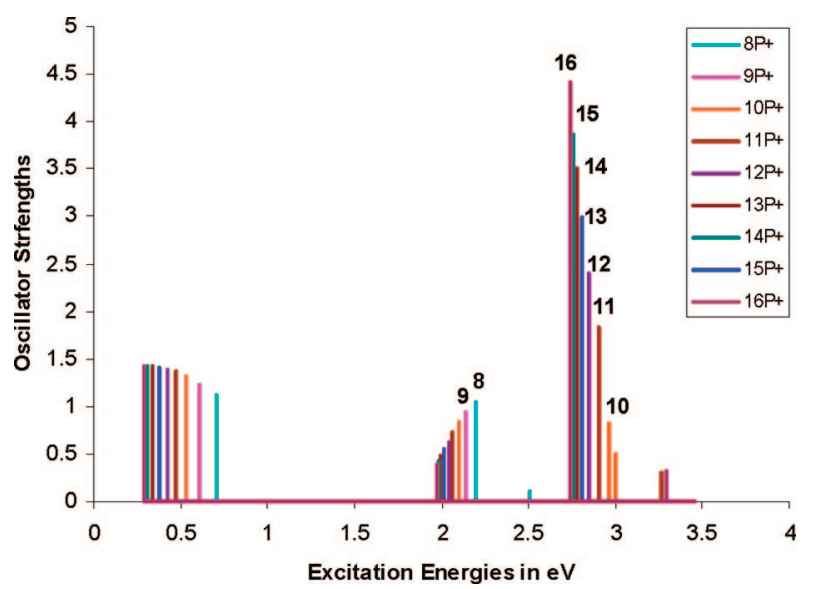

Figure 6. Stick spectra for $8 \mathrm{P}^{+}$through $16 \mathrm{P}^{+}$at the TDB3P86-30\% level.

The trend is that, in the presence of a counterion, E1 increases by about $0.3-0.4 \mathrm{eV}$ in energy and has slightly lower oscillator strength compared to E1 of bare cations. The energy of E2 is hardly affected, but the oscillator strength decreases a little. E3 is affected greatly. The oscillator strength of E3 is halved in the presence of a counterion and its energy is decreased by more than $0.6 \mathrm{eV}$. Finally, additional relatively weak transitions appear in the high-energy sub-band region. Electronic configurations contributing to E1, E2, E3, and E4 are depicted in Figure 11 for $13 \mathrm{P}-\mathrm{Cl}_{3}$. Compared to $13 \mathrm{P}^{+}$, the counterion causes more electron configurations to contribute to the electronic transitions and leads to further peak splitting, although none of the electronic transition involves the counterion. The solvent effect was calculated for $13 \mathrm{P}-\mathrm{Cl}_{3}$ and was found to be relatively small (Table 2).

Dications. Dications may have singlet (bipolaron), singlet biradical (polaron pair), or triplet ground states. Therefore openshell and closed-shell calculations were performed. At B3P86$30 \%$, the shortest oligomer that has a singlet instability is $4 \mathrm{P}^{2+}$. The closed-shell form lies $0.56 \mathrm{kcal} / \mathrm{mol}$ above the biradical, and the expectation value of the spin operator of the biradical 


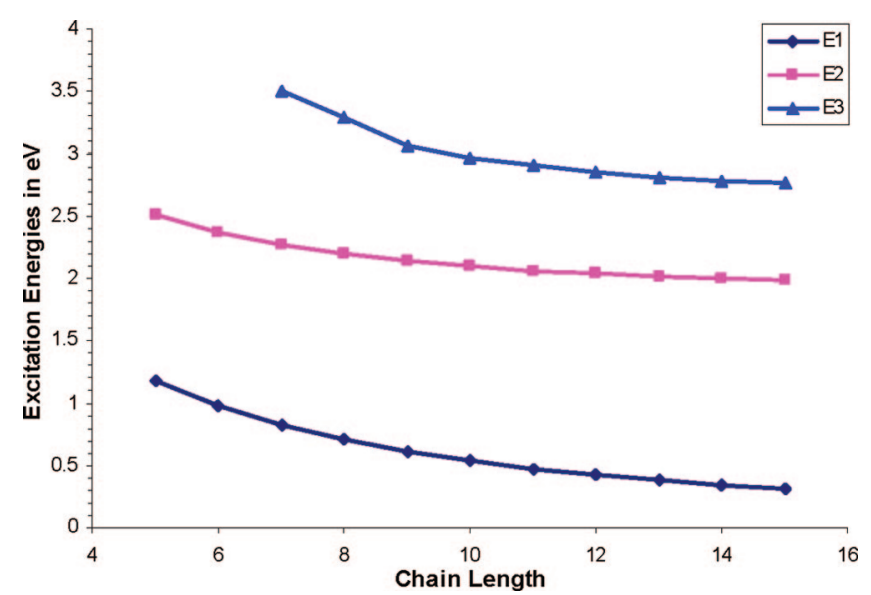

Figure 7. Development of the first three absorption energies for $2 \mathrm{P}^{+}$ through $16 \mathrm{P}^{+}$.

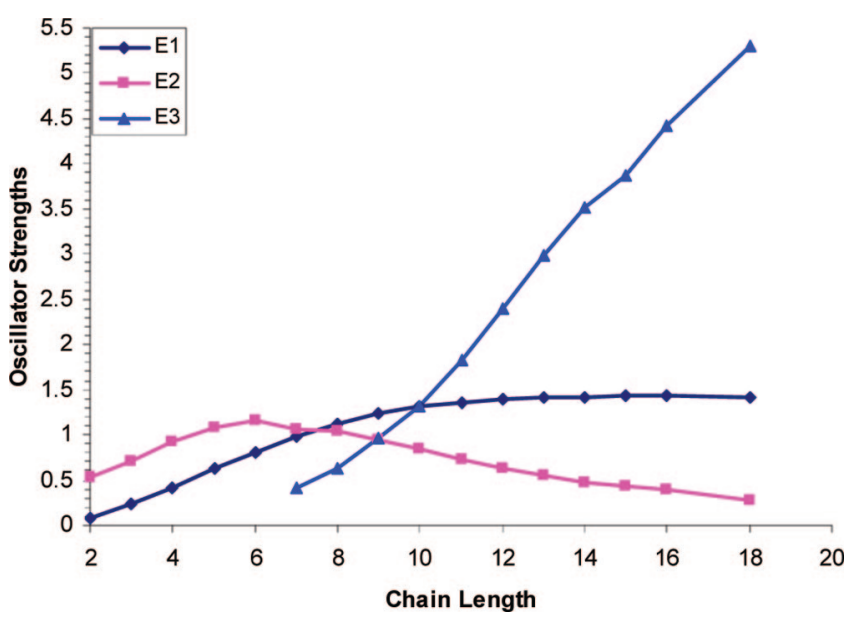

Figure 8. Oscillator strengths of the first three allowed singlet transitions of $2 \mathrm{P}^{+}$through $16 \mathrm{P}^{+}$. The oscillator strengths of the two close-lying peaks E3 and $\mathrm{E} 4$ of $9 \mathrm{P}^{+}$and $10 \mathrm{P}^{+}$were added.

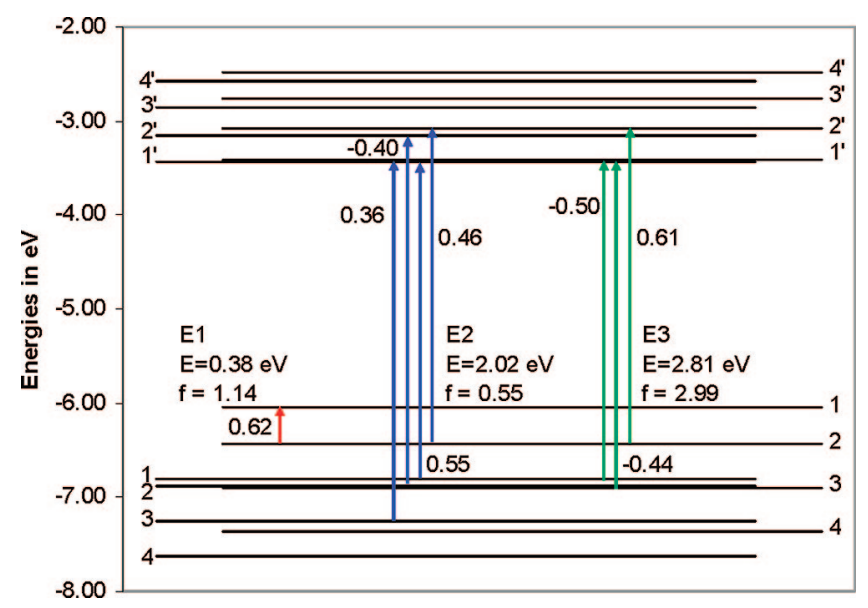

Figure 9. Electronic configurations contributing to the three strong sub-band transitions in $13 \mathrm{P}^{+}$at the TDB3P86-30\% level. The numbers close to the arrows give the coefficients of the transitions. $\beta$-Electron energy levels are shifted right with respect to the $\alpha$-levels.

$\left(\left\langle S^{2}\right\rangle\right)$ is 0.40 . With increasing chain length the preference for the biradical increases and the $\left\langle S^{2}\right\rangle$ value increases to 0.70 for $5 \mathrm{P}$ and 0.86 for $6 \mathrm{P}$, and converges to a value slightly above 1 for long chains. Since the $\left\langle S^{2}\right\rangle$ value equals 0 for a singlet and 2 for a triplet, an $\left\langle S^{2}\right\rangle$ value of 1 indicates an equal mixture of singlet and triplet states. This means that the proper ground state of all dications is a polaron pair and that the two electrons in the highest molecular orbitals do not interact significantly.

In short oligomers, the geometry distortion is spread over the whole chain. To investigate the preference without space restriction, larger oligomers have to be considered. Figure 12 illustrates geometry changes compared to the neutral form for $16 \mathrm{P}^{2+}$ closed and open shells. In both cases there is a tendency to separate the geometry distortion into two regions with the greatest distortion on the third ring from the terminals (around C12). The separation is more pronounced for the biradical but is also visible for the closed-shell singlet state. The geometry of the triplet state of $16 \mathrm{P}^{2+}$ (not shown) is practically identical to that of the singlet biradical, and both states are energetically degenerate.

Bipolaron formation can be forced by adding two closely spaced counterions as shown in Figure 13. In the first two structures (top and middle) counterions were placed next to the central rings and structures were optimized as closed-shell singlets. The tilt angle of the counterions indicates that the anions approach the positively charged hydrogen atoms of the pyrrole nitrogens. The first structure in Figure 13 is lower in energy than the second by $2.59 \mathrm{kcal} / \mathrm{mol}$. The third structure in Figure 13 (bottom) represents a polaron pair and is the minimum as it lies $0.66 \mathrm{kcal} / \mathrm{mol}$ below the first structure. Moving the counterions further toward the edges increases the energy. Thus polaron pair formation is confirmed in the presence of counterions and preference for polarons will probably increase at larger oligomer size. Geometry distortions in the first and third structures compared to neutral 12P are plotted in Figure 14.

Excitation energies for $2 \mathrm{P}^{2+}$ through $16 \mathrm{P}^{2+}$ are summarized in Table 3. Stick spectra of closed-shell dications are plotted in Figure 15and those of open-shell dications are plotted in Figure 16. Closed-shell dications of short oligomers have one absorption peak below the band gap of the neutral species. For $2 \mathrm{P}^{2+}$ the strong absorption is due to a 4-1 electronic transition; for all other oligomers, the lowest allowed excited state is dominated by a $2-1$ (HOMO-LUMO of the dication) transition. For medium-sized oligomers a second absorption arising from the $2-2^{\prime}$ transition appears in the energetic region of the $1-1^{\prime}$ transition of the neutral form. This absorption decreases in energy and increases in intensity with growing chain length. For $16 \mathrm{P}^{2+} \mathrm{E} 2$ is stronger than $\mathrm{E} 1$ and lies about $0.7 \mathrm{eV}$ below the TDHF band gap of neutral 16P.

Biradicals have two strong absorption peaks even at very short chain length. E1 arises from a linear combination of 2-1 and 3-1 transitions and lies lower than E1 of closed-shell species but decreases in energy more slowly so that starting with $8 \mathrm{P}^{2+}$ the open-shell form has a slightly higher lying E1. E2, which is a $2-1^{\prime}$ transition, increases rapidly in oscillator strength as the chain length increases. E2 remains lower in energy for the open-shell forms than for closed-shell species at all chain lengths. The development of excitation energies of closed-shell and open-shell species is compared in Figure 17. It is visible that the only significant difference between spectra of closedshell and open-shell forms of the dications is the lower energy of E2.

Compared to monocations the two excitation energies of open-shell dications occur at slightly higher energies as illustrated in Figure 18. The similarity of the excitation energies of cations and dications shows that it would be rather difficult to distinguish them experimentally from peak positions, especially when conjugation lengths are not known. Differences between cations and dications occur in the oscillator strengths, as E2 is stronger than E1 for short to medium-sized monoca- 


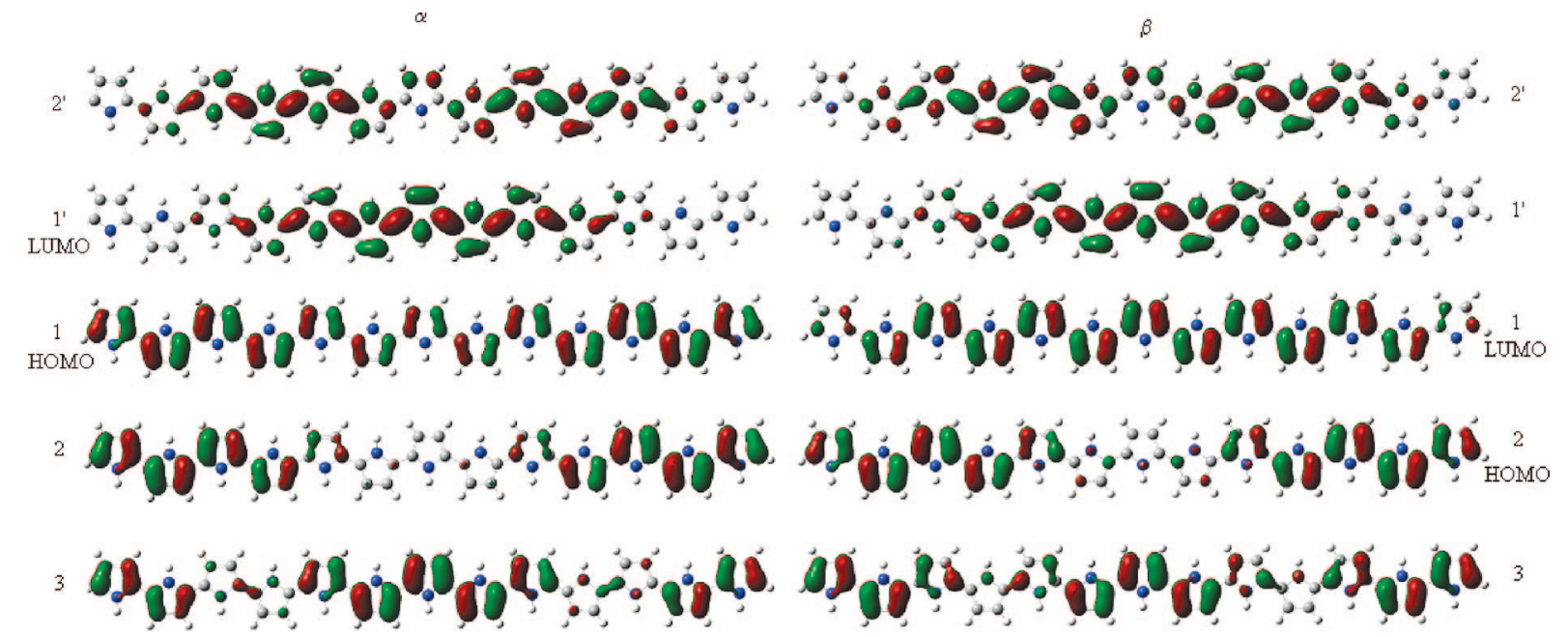

Figure 10. Orbitals 3 through $2^{\prime}$ of $13 \mathrm{P}^{+}$.

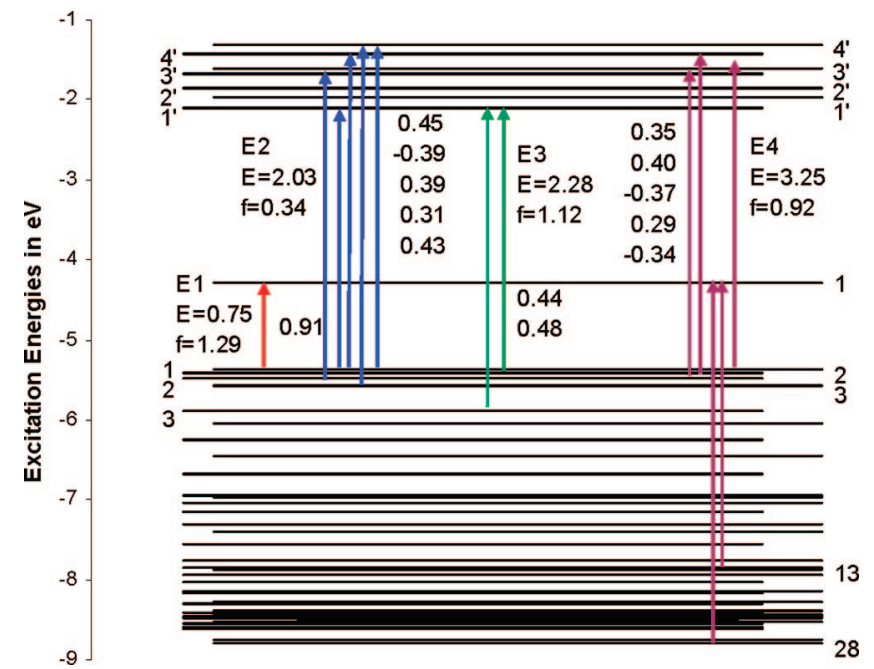

Figure 11. Electronic configurations contributing to the four strong sub-band transitions in $13 \mathrm{P}-\mathrm{Cl}_{3}$ at the TDB3P86-30\% level. The numbers close to the arrows give the coefficients of the transitions. $\beta$-Electron energy levels are shifted right with respect to the $\alpha$-levels.

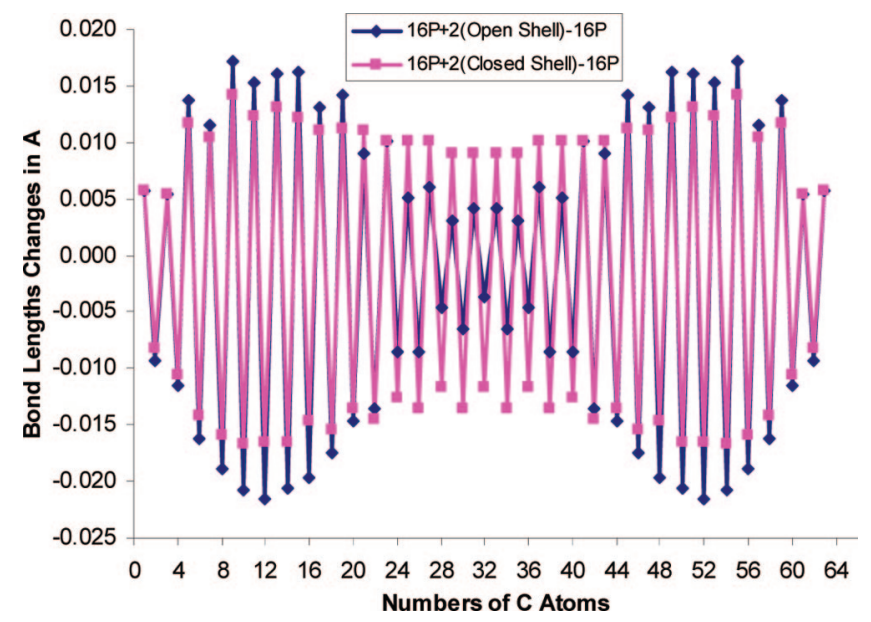

Figure 12. Geometry changes in $16 \mathrm{P}^{2+}$ closed-shell singlet and biradical compared to neutral $16 \mathrm{P}$.

tions, while the reverse is predicted for dications. For cations and dications the relative oscillator strengths of E1 and E2 switch for longer oligomers.
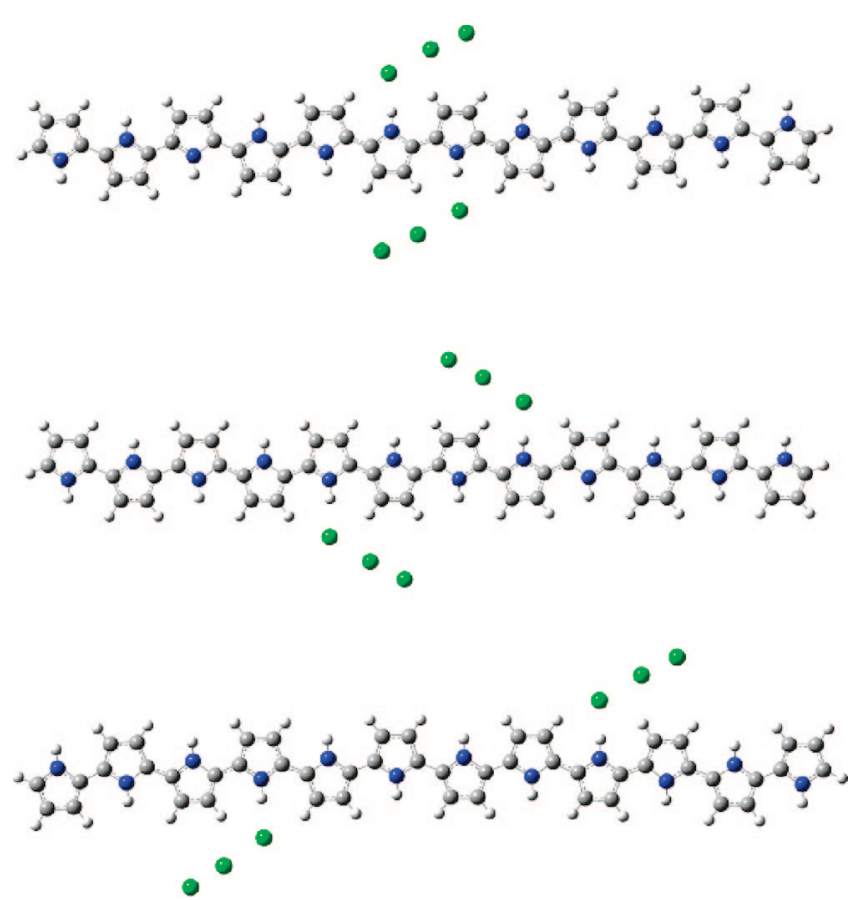

Figure 13. Optimized structures of $12 \mathrm{P}-\mathrm{Cl}_{3}$ to create polaron- and bipolaron-like geometry distortions.

\section{Discussion}

Accuracy Issues. Compared to solution experiments, two effects are missing in gas phase calculations: possible deviation from planarity and missing solvent effects. Only $2 \mathrm{P}$ was investigated in matrix at low temperature. ${ }^{48}$ The excitation energy was found to be $0.43 \mathrm{eV}$ lower in matrix than in solution. The lower value in matrix is consistent with increased planarity, although Birnbaum and Kohler suggested that 2P may not be completely planar in matrix. We checked the effect of nonplanarity for $2 \mathrm{P}$ and $4 \mathrm{P}$. The dihedral angle between the two rings in $2 \mathrm{P}$ was optimized to $23^{\circ}$. Nonplanarity lowers the total energy by $0.13 \mathrm{kcal} / \mathrm{mol}$. The first strong excitation at the TDHF level increases by $0.14 \mathrm{eV}$ (4.97 eV (planar) and $5.12 \mathrm{eV}$ (nonplanar), $0.3 \mathrm{eV}$ less than the difference between solution and matrix experiments. Almost no preference for twisting was found for $4 \mathrm{P}$, and the slightly twisted form has a $0.08 \mathrm{eV}$ higher excitation energy than the planar form (4.03 eV (planar) and $4.11 \mathrm{eV}$ (nonplanar)). These results are in agreement with data reported by Millefiori et al., ${ }^{64}$ who predicted based on trends in torsional 


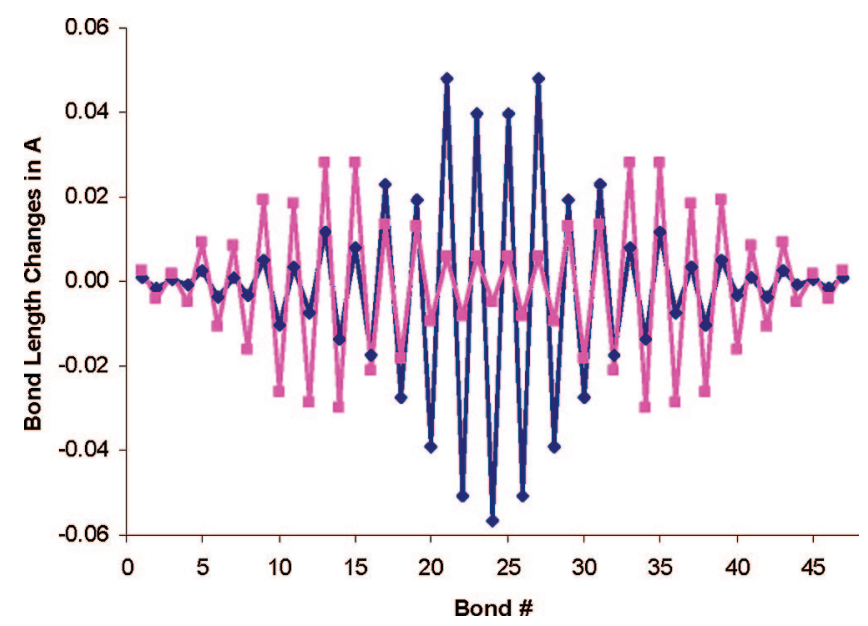

Figure 14. Geometry distortions of bipolaron and polaron pair forms of $12 \mathrm{P}-\left(\mathrm{Cl}_{3}\right)_{2}$.

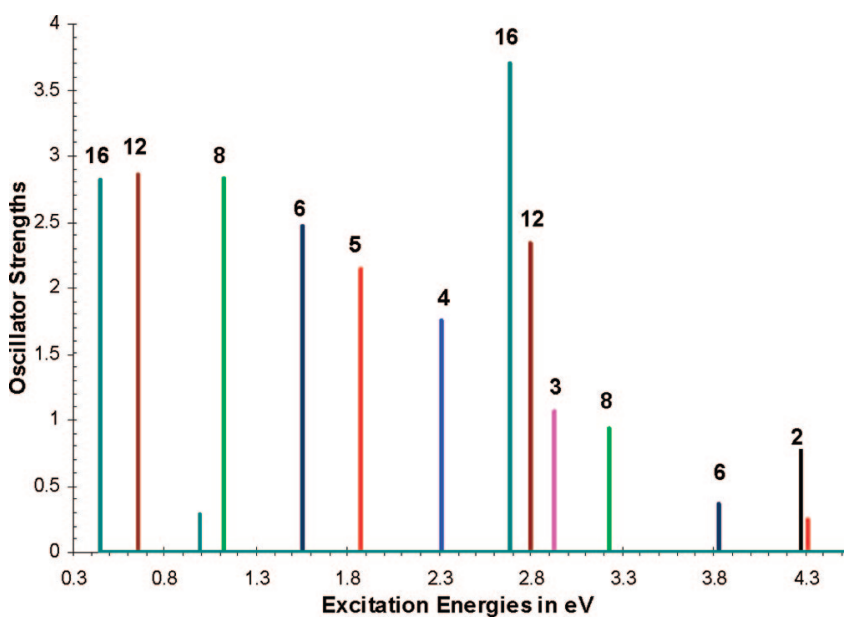

Figure 15. TDB3P86-30\% excitation energies of closed-shell $2 \mathrm{P}^{2+}$ through $16 \mathrm{P}^{2+}$.

TABLE 3: TDB3P86-30\% Excitation Energies of 2P through 16P Dications in Singlet (Closed-Shell) and Biradical (Open-Shell) States

\begin{tabular}{lll}
\hline & \multicolumn{1}{c}{ E1 } & E2 \\
\hline 2 & $4.27(0.76)$ & \\
3 & $2.93(1.07)$ & \\
4, closed shell & $2.31(1.75)$ & \\
4, open shell & $2.04(0.81)$ & $2.47(0.56)$ \\
5, closed shell & $1.87(2.14)$ & \\
5, open shell & $1.69(1.38)$ & $3.03(0.29)$ \\
6, closed shell & $1.56(2.47)$ & $3.83(0.36)$ \\
6, open shell & $1.43(1.60)$ & $2.72(0.58)$ \\
8, closed shell & $1.12(2.83)$ & $3.22(0.94)$ \\
8, open shell & $1.09(1.83)$ & $2.51(1.29)$ \\
12, closed shell & $0.66(2.86)$ & $2.80(2.34)$ \\
12, open shell & $0.72(2.19)$ & $2.28(2.11), 2.41(0.32)$ \\
16, closed shell & $0.45(2.81)$ & $2.69(3.70)$ \\
16, open shell & $0.49(2.41)$ & $2.12(0.51), 2.14(0.75), 2.21(1.22)$
\end{tabular}

potentials that PPy is probably planar in the long-chain limit. Nonetheless, energetic preferences for twisted structures amount to $1.3 \mathrm{kcal} / \mathrm{mol}$ for $6 \mathrm{P}$ and $9.2 \mathrm{kcal} / \mathrm{mol}$ for $30 \mathrm{P}$ according to Zade and Bendikov. ${ }^{70}$

Comparison between DFT and MP2 torsional potentials obtained with small basis sets seems to indicate that DFT underestimates the energies of planar structures compared to distorted ones. However, it has been shown convincingly that this is due not to problems with DFT but to basis set

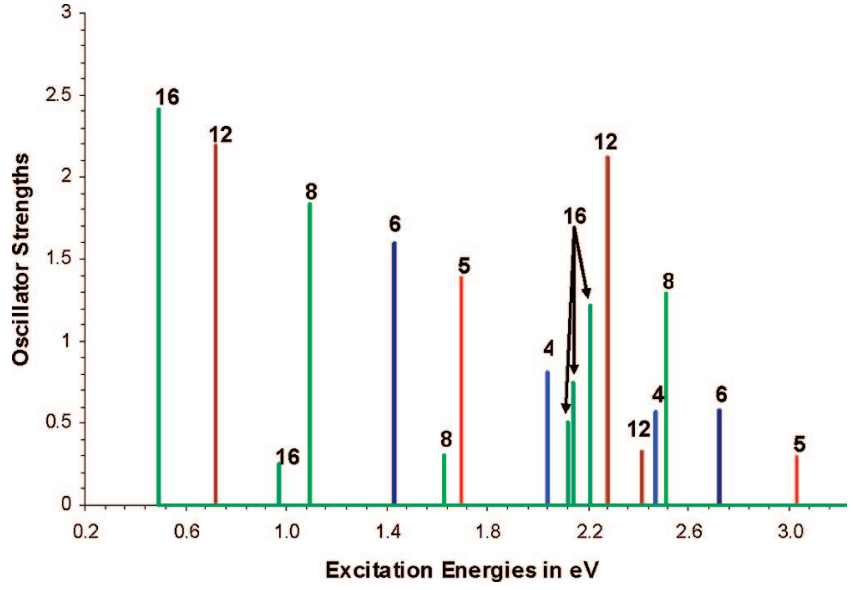

Figure 16. TDB3P86-30\% excitation energies of open-shell $4 \mathrm{P}^{2+}$ through $16 \mathrm{P}^{2+}$.

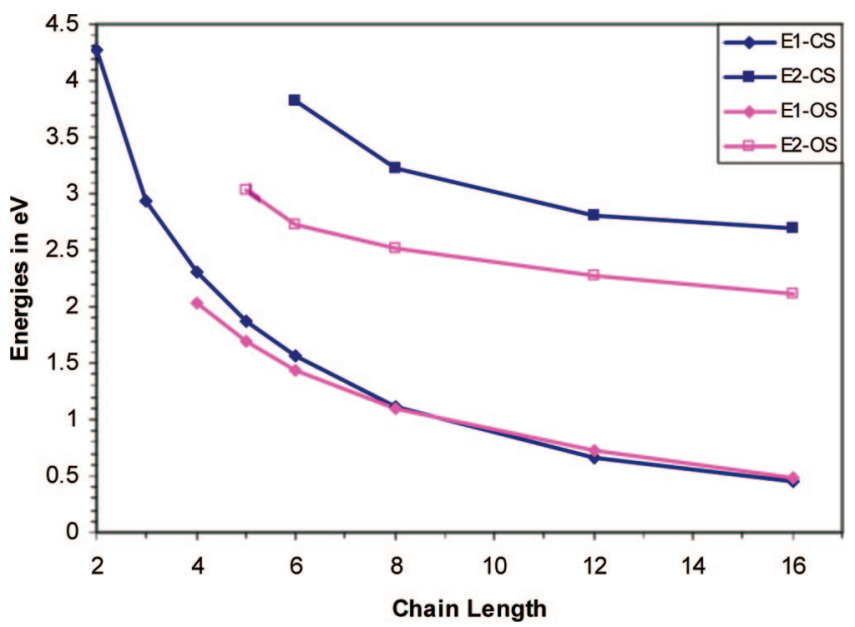

Figure 17. TDB3P86-30\% excitation energies of closed-shell and open-shell dications.

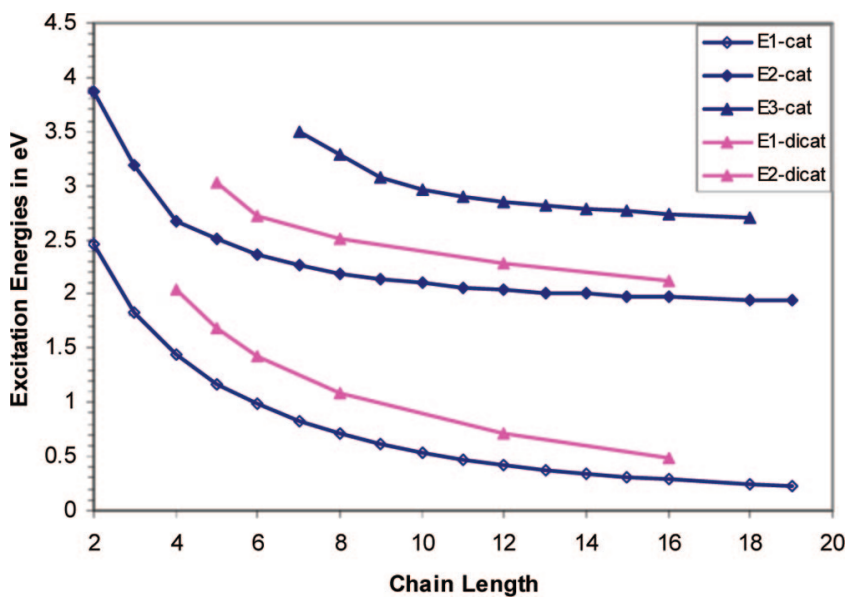

Figure 18. Comparison of excitation energies of mono- and dications of OPs.

insufficiency at the MP2 level. ${ }^{64,91,92}$ Inclusion of zero point vibrational corrections flattens the potential energy surfaces further. ${ }^{64}$ Thus, geometries of pyrrole oligomers are quite flexible and planarization energies are small. We assume therefore planar structures for short oligomers and attribute short conjugation length in PPy (see below) to the increasing tendency of long chains to distort from planarity.

Solvent effects were calculated for $2 \mathrm{P}$ and $5 \mathrm{P}$ with the PCM method using $\mathrm{CH}_{2} \mathrm{Cl}_{2}$ as solvent. Solvent reduces the excitation 
energies of $2 \mathrm{P}$ and $5 \mathrm{P}$ by 0.13 and $0.10 \mathrm{eV}$, respectively. Since solvent effects lower excitation energies slightly and nonplanarity tends to increase them by a comparable amount, the two effects cancel roughly. No substantial error is therefore introduced by using planar gas phase results. Since Figure 1 shows that the predicted excitation energies are $0.4-0.5 \mathrm{eV}$ too high, we tested the effect of basis set enlargement. We recalculated $2 \mathrm{P}$ excited states with $6-31+\mathrm{G}^{* 84}$ and with correlation-consistent polarized valence quadruple- $\zeta$ (CC-PVQZ) basis sets. ${ }^{85}$ With both basis sets the excitation energy is reduced by $0.16 \mathrm{eV}$. The match between the $6-31+\mathrm{G}^{*}$ and the CC-PVQZ basis sets indicates that the excitation energy is converged with respect to basis set size. Since basis set issues tend to become less important as the systems get larger, even smaller corrections are expected by improving sets for longer oligomers. Thus the error in the excitation energies of neutral species must be in the TDHF method.

A literature search for benchmark calculations revealed that high-level ab initio calculations are published only for pyrrole ${ }^{93-96}$ and not for longer oligomers. The best estimate at the coupledcluster level for the $\pi-\pi^{*}$ transition of pyrrole, $6.57 \mathrm{eV}$, is even higher than our TDHF value of $6.47 \mathrm{eV}$. Often theoretical difficulties encountered with small systems disappear when larger species are treated. For instance, in the polyene series butadiene causes the biggest problems whereas results for hexatriene and octatetraene are less prone to theoretical difficulties. ${ }^{97}$ Likewise, the error for thiophene at the TDHF level, $0.63 \mathrm{eV}$, is substantial but TDHF results, including the solvent effect, for tetrathiophene overestimate experimental results ${ }^{48}$ by only $\sim 0.3 \mathrm{eV}$ and excitation energies of longer oligomers converge toward experimental results. Table 1 and Figure 1 show that this is not the case for pyrrole oligomers, since the error at TDHF remains constant over the whole series. It would be tempting at this point to use the TDB3P86-30\% results, which are clearly closer to experiment. The slopes of TDBP86 and TDB3P86-30\% results (Figure 1) reveal, however, that the smaller error at TDBP86-30\% is due to error cancellation between overestimation of excitation energies of short oligomers and too fast a decrease with increasing chain length. Therefore we decided to continue using TDHF for neutral oligomers.

For charged species of known conjugation length only Zotti et al.' $\mathrm{s}^{47}$ investigation of $5 \mathrm{P}^{+}$and $5 \mathrm{P}^{2+}$ is available for comparison. As one of the reviewers pointed out, no characterization has been published for pyrrole oligomers with more than three rings. Therefore the experimental results must be viewed with some caution. For $5 \mathrm{P}^{+}$one sub-band absorption was reported at $2.19 \mathrm{eV}$. TDB3P86-30\% predicts two sub-band features at 1.17 and $2.51 \mathrm{eV}$ for the naked cation. Two subband peaks are also found theoretically and experimentally for thiophene oligomer radical cations. ${ }^{33,40,41,83}$ As the $1.17 \mathrm{eV}$ peak lies outside the spectral range shown in ref 47 , it might be confirmed, if the spectral range were increased. The higher energy feature is overestimated by $0.3 \mathrm{eV}$ with TDB3P86-30\%. Since radical cations have increased double bond strength in the inter-ring bonds, they are planar in solution as confirmed by a frequency calculation. Using planar structures does therefore not introduce errors for charged species. With one $\mathrm{Cl}_{3}{ }^{-}$ counterion in $\mathrm{CH}_{2} \mathrm{Cl}_{2}$, the two peaks shift only slightly to 1.16 and $2.46 \mathrm{eV}$. Thus, the error for pyrrole species is again larger than for thiophene cations but smaller than for neutral pyrrole oligomers. The dication of $5 \mathrm{P}$ absorbs at $1.57 \mathrm{eV},{ }^{47}$ which is $0.3 \mathrm{eV}$ below the value predicted for the closed-shell dication $(1.87 \mathrm{eV})$ but close to that for the biradical $(1.69 \mathrm{eV})$. Thus all
TABLE 4: Experimental UV Data on PPy and OPs (in eV)

\begin{tabular}{|c|c|c|c|}
\hline reference & neutral & cation & dication \\
\hline Street $^{52}$ Diaz $^{42}$ & & & \\
\hline monomer & 5.96 & & \\
\hline dimer & 4.35 & & \\
\hline trimer & 3.59 & & \\
\hline polymer & 3.02 & & \\
\hline polymer & 3.2 & \multicolumn{2}{|c|}{ oxidized; 1.3} \\
\hline $\begin{array}{l}\text { Pfluger }{ }^{14} \\
\text { polymer }\end{array}$ & $\begin{array}{l}0.8 / 1.4 / 2.1 / \\
3.1\end{array}$ & $\begin{array}{l}\text { low doping; } \\
0.8 / 1.4 / 2.1 / 3.1\end{array}$ & $\begin{array}{l}\text { high doping; } \\
\text { 1.0/3.4/4.2 }\end{array}$ \\
\hline $\begin{array}{l}\text { Yakushi }^{12} \\
\text { polymer }\end{array}$ & $3.2 / 4.5 \mathrm{sh}$ & $0.7 / 1.4 / 2.1$ & $\begin{array}{l}\text { as grown; } \\
1.0 / 2.7 / 3.6\end{array}$ \\
\hline $\begin{array}{l}\text { Kaufmann } \\
\text { polymer }^{16} \\
\text { Fink }^{13}\end{array}$ & 3.20 & 1.2 & $0.7 / 2.30 / 3.20$ \\
\hline $\begin{array}{l}\text { polymer } \\
\text { Zotti }^{18}\end{array}$ & 3.20 & 0.8/2.2/gap: 2.5 & 1.5-2.0/3.0/gap: 3.5 \\
\hline $\begin{array}{l}\text { polymer } \\
\text { Plugh }^{100}\end{array}$ & 3.10 & 2.30 & 1.38 \\
\hline$\sim 10$ rings & & $1.26 / 2.6$ & \\
\hline $\begin{array}{l}\text { Birnbaum } \\
\text { dimer } \\
\text { Zotti }^{47}\end{array}$ & 4.06 & & \\
\hline monomer & 5.96 & & \\
\hline dimer & 4.49 & & \\
\hline trimer & 3.91 & & \\
\hline pentamer & 3.38 & 2.19 & 1.57 \\
\hline heptamer & 3.25 & & \\
\hline polymer & 2.85 & & \\
\hline $\begin{array}{l}\text { Guyard }^{45} \\
\text { dimethyl } \\
\text { tetramer }\end{array}$ & 3.54 & 2.30 & 1.82 \\
\hline $\begin{array}{l}\text { Rapta }^{25} \\
\text { polymer } \\
\text { Wenbo } \\
\text { (substituted) }\end{array}$ & 3.10 & 2.06 & 1.38 \\
\hline dimer & 4.00 & 3.00 & 1.92 \\
\hline trimer & 3.87 & 2.58 & $1.45 / 1.59$ \\
\hline tetramer & 3.87 & 2.48 & 1.77 \\
\hline
\end{tabular}

theoretical estimates for OPs are upper bounds and the error seems to decrease from neutral to singly and doubly charged species.

Analysis of Pyrrole Oligomers and PPy. Polypyrrole has been investigated intensively. Representative experimental data are summarized in Table 4. Most experimental studies agree that neutral PPy has a maximum absorption at 3.0-3.2 $\mathrm{eV}, 16,18,25,52$ although Zotti et al.'s oligomer data converge to a smaller value, $2.85 \mathrm{eV} .{ }^{47}$ Lightly doped PPy exhibits two subband features at $0.7-0.8$ and $2.1-2.3 \mathrm{eV} \cdot{ }^{12,13,16,18}$ In addition, Yakushi et al. ${ }^{12}$ reported an absorption at $1.4 \mathrm{eV}$ that they attributed to oxidation by oxygen. Reactions of oxygen at the pyrrole nitrogen were also reported by other groups. ${ }^{14,98}$ At higher doping levels both bands shift to higher energy and two absorptions occur at 1.0 and $2.7 \mathrm{eV} .{ }^{12}$ In contrast, Street et al. ${ }^{52}$ reported an absorption energy of $1.3 \mathrm{eV}$ after oxidation with oxygen, Zotti et al. ${ }^{18}$ and Rapta et al. ${ }^{25}$ observed a band at 1.38 $\mathrm{eV}$, and Fink et al. ${ }^{13}$ found two peaks at $1.5-2.0 \mathrm{eV}$ and at 3.0 $\mathrm{eV}$ with electron energy loss spectroscopy at higher doping levels. Although there are significant differences in reported data and in the interpretation of experimental results, on combining polymer and oligomer data the following picture emerges: (1) since the absorption maximum of polypyrrole is close to that or slightly below that of 7P, conjugation length in PPy is likely in the range of seven to nine rings (as found also with Raman spectroscopy ${ }^{99}$ ); (2) monocations and polarons give rise to two sub-band peaks at about $0.7-0.8$ and $2.1-2.3 \mathrm{eV}$, while dications or bipolarons have a characteristic absorption in the range $1.0-1.4 \mathrm{eV}$. The "uniquely polaron peak" at $1.2 \mathrm{eV}$ that was used by Kaufman et al. ${ }^{16}$ to investigate recombination of polarons into bipolarons is most likely a bipolaron peak. 


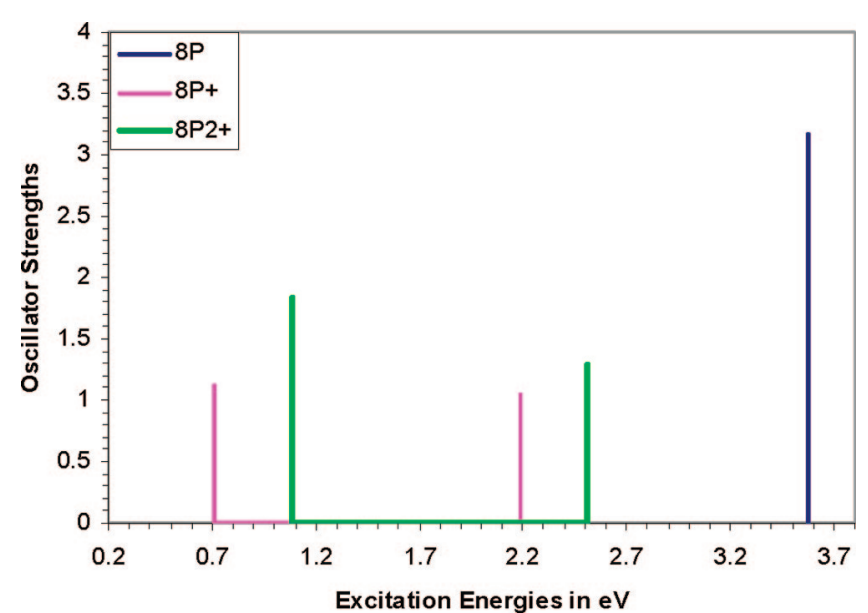

Figure 19. Absorption peaks for $8 \mathrm{P}(\mathrm{TDHF}), 8 \mathrm{P}^{+}$, and $8 \mathrm{P}^{2+}$ (TDB3P86$30 \%)$.

Theoretical data predict changes in spectra for cations and dications caused by configuration interaction when the chain length increases beyond seven to nine rings. As mentioned above, comparing experimental oligomer and polymer data suggests that the conjugation length in neutral PPy is about seven to nine rings. Therefore, the spectral changes predicted for long oligomers are probably not observed in experiment. Hence, for comparison between theory and experiment, $6 \mathrm{P}-8 \mathrm{P}$ appear to be good models.

For these medium-sized oligomers, theory predicts two peaks for cations and dications. Figure 19 shows stick spectra for 8P, $8 \mathrm{P}^{+}$, and $8 \mathrm{P}^{2+}$. The relative oscillator strengths are reversed for cations and dications. E1, being originally weaker than E2 for cations, becomes equal to $\mathrm{E} 2$ at $8 \mathrm{P}^{+}$. For the dications $\mathrm{E} 1$ is stronger at this chain length. Excitation energies for $6 \mathrm{P}^{+}$and $8 \mathrm{P}^{+}$are 0.98 and $0.71 \mathrm{eV}(\mathrm{E} 1)$, and 2.36 and $2.19 \mathrm{eV}(\mathrm{E} 2)$. Dications give rise to two peaks between $1.09-1.43 \mathrm{eV}$ and $2.51-2.72 \mathrm{eV}$. This is precisely the range of the experimental data for low and high doping levels of PPy. Taking into account that the theoretical results are upper bounds, this indicates that conjugation lengths in PPy must be below eight rings. The big change in $\mathrm{E} 1$ for dications between $6 \mathrm{P}^{2+}$ and $8 \mathrm{P}^{2+}$ suggests that the wide range of peak positions observed experimentally at high doping levels is due to slightly different conjugation lengths.

An interesting difference between PPy and PTh is the appearance of the $1.4 \mathrm{eV}$ feature in some experiments at low doping levels in PPy. TDB3P86-30\% data show that the only peak in this region is E1 for the $6 \mathrm{P}^{2+}$ (closed and open shell). Two charges per six rings correspond to a doping level of $33 \%$, the highest that can be achieved experimentally. We find no indication, however, for the presence of a band around $1.4 \mathrm{eV}$ for cations that would account for appearance of the $1.4 \mathrm{eV}$ peak at low doping levels. Theoretically, there are no peaks whatsoever predicted around $1.4 \mathrm{eV}$ for cations with more than four rings. Alternatively, the $1.4 \mathrm{eV}$ absorption might be due to reaction with oxygen as suggested by Yakushi. ${ }^{2}$ Reaction of polypyrrole with of oxygen atoms during doping was also reported by Pfluger et al. ${ }^{14}$

Comparison of Pyrrole Oligomers with Thiophene Oligomers. The first allowed excited state of thiophene and pyrrole oligomers is dominated by the HOMO-LUMO $\left(1-1^{\prime}\right)$ transition, although the configuration interaction coefficient of the $1-1^{\prime}$ transition decreases from $\sim 0.7$ for dimers to $\sim 0.4$ at long chain length. Excitation energies of neutral thiophene and

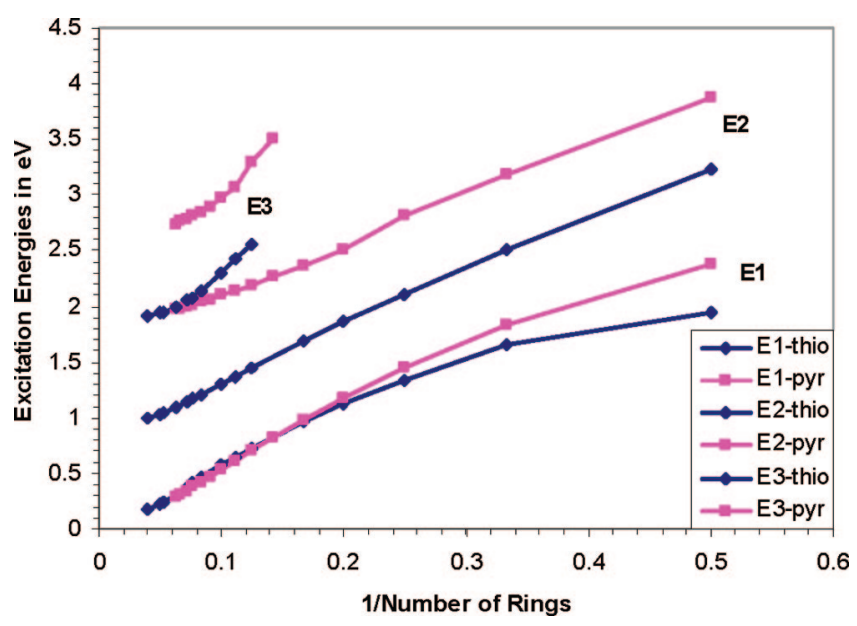

Figure 20. TDB3B86-30\% sub-band transitions for oligothiophene and oligopyrrole cations with $2-19$ rings.

pyrrole oligomers are compared in ref 101. At all chain lengths thiophene oligomers have smaller HOMO-LUMO $\left(1-1^{\prime}\right)$ gaps and lower excitation energies than pyrrole oligomers. For thiophene oligomers the excitation energies converge to $2.5 \mathrm{eV}$ in the long-chain limit. The limiting value for pyrrole oligomers is about $3.3 \mathrm{eV}$. Thus the difference, $0.8 \mathrm{eV}$, is $0.3 \mathrm{eV}$ larger than the experimental difference between $2.7 \mathrm{eV}$ (PTh) and $3.1-3.2 \mathrm{eV}$ (PPy).

Cations of thiophene and pyrrole oligomers are predicted to have two sub-band absorptions at short chain lengths and three for longer oligomers. E1 is dominated by the $2-1$ transition which involves orbitals corresponding to HOMO and HOMO -1 of the neutral from. The energy difference between these two levels is similar in thiophene and pyrrole oligomer cations. E2 arises from the $1-1^{\prime}$ transitions between orbitals that correspond to HOMO and LUMO of the neutral species. Because the HOMO-LUMO gap is larger in neutral pyrrole than in neutral thiophene oligomers, the $1-1^{\prime}$ energy difference is also larger for the oligopyrrole cations. E3 involves configuration interaction but has a strong $1-1^{\prime}$ contribution. In Figure 20, E1, E2, and E3 are compared for thiophene and pyrrole oligomers with 2-19 rings. E1 converges to the same value for both series. The difference for short oligomers is due to mixing in of the $1-1^{\prime}$ transitions. As the $2-1$ transition becomes dominant, the energies become identical. E2 and E3 are always higher in energy for OPs and for OTs. Dications (not shown) exhibit similar behavior. E1 is almost identical for OPs and OTs; E2 and E3 are larger for pyrrole species. All these results are consistent with the energy level differences between 2, 1, and $1^{\prime}$ orbitals. In summary, the behavior of pyrrole oligomers upon doping is completely analogous to that of thiophene oligomers. No extra bands are calculated for pyrrole oligomers.

Stability of Polarons vs Bipolarons. Bipolaron formation was invoked to explain conductivity of conducting polymers in the absence of ESR signals and the lack of correlation between conductivity and the number of spins..$^{16,22}$ Other experiments were shown to be in agreement with preference for polaron formation, ${ }^{17,23,24,102}$ energetic degeneracy between polarons and bipolarons, ${ }^{25}$ and coexistence of polarons and bipolarons. ${ }^{26}$ Theoretically bipolaron formation was promoted by Bredas et al.,, 920 who calculated a bipolaron binding energy of $0.45 \mathrm{eV}$ for polypyrrole with the tight binding method..$^{58}$ The driving force for recombination of polarons and overcoming the Coulomb repulsion between two positively charged defects is gain in lattice relaxation energy when the two charges are 


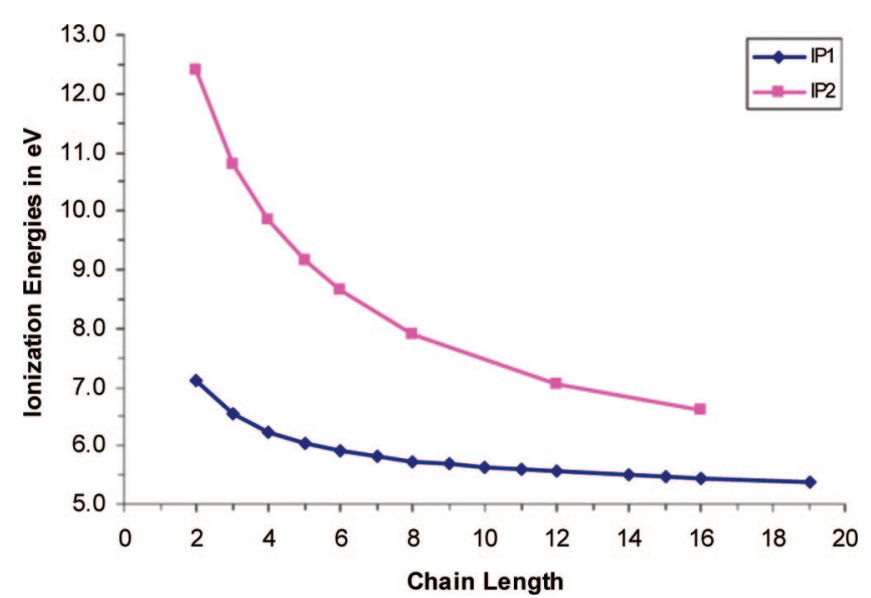

Figure 21. First and second ionization energies of $2 \mathrm{P}-19 \mathrm{P}$.

coupled to the same lattice mode. ${ }^{103}$ Stability of bipolarons was confirmed with self-consistent CNDO calculations. ${ }^{103}$ In contrast, the Pariser-Parr-Pople approximation predicts preference for polarons at low doping levels. ${ }^{104}$ Density functional theory, with and without Hartree-Fock exchange, does not predict bipolaron formation. ${ }^{83,105-113}$ Preference for polaron pairs is confirmed in the presence of counterions for thiophene oligomers. ${ }^{113}$ Analysis of the differences between ab initio (HartreeFock, MP2) and DFT results has shown that inclusion of correlation reduces defect localization and that DFT and MP2 are in general agreement. ${ }^{71,104,109,110,114}$ DFT is therefore an improvement over earlier uncorrelated ab initio and semiempirical methods. DFT is also the method of choice since it is the only approach that can handle long $\pi$-conjugated radicals without spin contamination in the unrestricted open-shell formalism. ${ }^{71,72}$

Since bipolaron formation depends crucially on reduced lattice energy when two charges occupy the same site, it is an interesting question whether a bipolaron indeed causes a similar distortion as a polaron at a similar energy cost. To test this claim, the counterions were removed from the first and third structures shown in Figure 13 and single point calculations were carried out for neutral 12P using the two geometries. The lattice distortion energy of the bipolaron was found to be $15.3 \mathrm{kcal} /$ mol compared to fully optimized $12 \mathrm{P}$; the polaron pair requires $8.8 \mathrm{kcal} / \mathrm{mol}$. Thus there is no saving in lattice energy by bipolaron formation as the lattice distortion energy is less for two polarons than for a bipolaron by $6.5 \mathrm{kcal} / \mathrm{mol}$.

The present DFT calculations thus indicate that polaron pairs are preferred over bipolarons for several reasons. (1) Ground states of dications are biradicals and closed-shell species are higher in energy for all oligomers with more than three rings; (2) defects separate into two regions, for open-shell species but also for closed-shell species (Figure 12); (3) IP2 is always higher than IP1 (see Figure 21); (4) lattice distortion costs less energy for two polarons than for a bipolaron; (5) predicted spectra using polaron pairs agree better with experiment than those of bipolarons. The energy difference between polaron pairs and bipolarons in the presence of counterions is very small: 0.66 $\mathrm{kcal} / \mathrm{mol}$ for $12 \mathrm{P}\left(\mathrm{Cl}_{3}\right)_{2}$. This explains why several experiments ${ }^{25,26}$ found coexistence of polarons and bipolarons at low doping levels and why it is possible to reach high doping levels. Since polaron pairs prefer singlet over triplet ground states for small to medium-sized oligomers, the preference for two polarons on the same chain is not in contradiction with experiments that revealed that conduction is possible in the absence of free spins.
At high doping levels bipolaron-like species form because of space confinement although there is no bipolaron binding energy.

\section{Conclusions}

TDDFT calculations as well as experimental results are less accurate for pyrrole species than for thiophene oligomers and polyenes. Nonetheless, predicted spectra agree well with experiment. Comparison of DFT results with experimental data leads to the following description of the doping process: Polypyrrole samples have rather short conjugation lengths, approximately six to eight rings. Upon doping polarons form. In the presence of counterions relaxed polarons are about 9-11 rings wide. Thus conjugation lengths in PPy are shorter than relaxed polarons. Polaron formation is associated with appearance of two subband features in UV spectra.

At higher doping levels polaron pairs form on the same chain. There is no energy gain in lattice relaxation energy associated with bipolaron formation that could overcome the Coulomb repulsion between the like-charged defects. We believe that this shows convincingly that bipolarons are unstable, although the accuracy of the present calculations is very close to the energy difference between polaron pairs and bipolarons. These findings agree with earlier findings on thiophene oligomers and support the view that bipolaron binding of up to $0.5 \mathrm{eV}$ is an artifact of low-level theoretical methods.

At high doping levels, polarons on the same chain are confined and forced to overlap as conjugated chain segments are substantially shorter than the size of two polarons. Reaching high doping levels is possible because the repulsion between two polarons is weak in the presence of counterions $(0.66 \mathrm{kcal} /$ mol for $\left.12 \mathrm{P}-\left(\mathrm{Cl}_{3}\right)_{2}\right)$. Like separated polarons, overlapping polarons produce two sub-band transitions in UV spectra. The energies of the sub-band features of overlapping polarons are higher than those of separated polarons.

If conjugation lengths were to be increased substantially, changes in spectra, namely the appearance of additional peaks, is predicted. Additional peaks arise because for very long oligomers energy levels are getting closer and closer and configuration interaction is getting stronger.

Acknowledgment. S.O. thanks Prof. Cemil Öğretir for his encouragement and for stimulating discussions. This work was supported by Bilkent University, Ulakbim (TR-GRID-NGI), and by TÜBITAK (TBAG-2461).

\section{References and Notes}

(1) McNeil, R.; Siudak, R.; Wardlaw, J. H.; Weiss, D. E. Aust. J. Chem. 1963, 16, 1056.

(2) Bolto, B. A.; Weiss, D. E. Aust. J. Chem. 1963, 6, 1076. 1090 .

(4) Chiang, C. K.; Fincher, C. R.; Park, Y. W.; Heeger, A. J.; Shirakawa, H.; Louis, E. J.; Gau, S. C.; MacDiarmid, A. G. Phys. Rev. Lett. 1977, 39, 1098.

(5) Shirakawa, H.; Louis, F. J.; MacDiarmid, A. G.; Chiang, C. K.; Heeger, A. J. J. Chem. Soc., Chem. Commun. 1977, 578.

(6) Skotheim, T. A. Handbook of Conducting Polymers; Marcel Dekker: New York, 1986.

(7) Handbook of Conducting Polymers, 2nd ed.; Skotheim, T. A., Elsenbaumer, R. L., Reynolds, J. R., Eds.; Marcel Dekker, Inc.: New York, 1997.

(8) Kanazawa, K. K.; Diaz, A. F.; Geiss, R. H.; Gill, W. D.; Kwak, J. F.; Logan, J. A.; Rabolt, J. F.; Street, G. B. J. Chem. Soc., Chem. Commun. 1979, 854.

(9) Brédas, J. L.; Street, G. B. Acc. Chem. Res. 1985, 18, 309.

(10) Kaiser, A. B. Adv. Mater. 2001, 13, 927.

(11) Patil, A. O.; Heeger, A. J.; Wudl, F. Chem. Rev. 1988, 88, 183. 
(12) Yakushi, K.; Lauchlan, L. J.; Clarke, T. C.; Street, G. B. J. Chem Phys. 1983, 79, 4774 .

(13) Fink, J.; Scheerer, B.; Wernet, W.; Monkenbusch, M.; Wegner, G.; Freund, H. J.; Gonska, H. Phys. Rev. B 1986, 34, 1101.

(14) Pfluger, P.; Krounbi, M.; Street, G. B.; Weiser, G. J. Chem. Phys. 1983, 78, 3212.

(15) Chung, T.-C.; Kaufman, J. H.; Heeger, A. J.; Wudl, F. Phys. Rev.

$B$ 1984, 30, 702 .

(16) Kaufman, J. H.; Colaneri, N.; Scott, J. C.; Street, G. B. Phys. Rev. Lett. 1984, 53, 1005 .

(17) Genoud, F.; Guglieli, M.; Nechtschein, M.; Genies, E. M. S. Phys. Rev. Lett. 1985, 55, 118.

(18) Zotti, G.; Schiavon, G. Synth. Met. 1989, 30, 151.

(19) Brédas, J. L.; Thémans, B.; André, J.-M.; Chance, R. R.; Silbey,

R. Synth. Met. 1984, 9, 265.

(20) Brédas, J. L.; Scott, J. C.; Yakushi, K.; Street, G. B. Phys. Rev. $B$ 1984, 30, 1023 .

(21) Brédas, J. L. J. Mol. Struct. (THEOCHEM) 1984, 107, 169.

(22) Scott, J. C.; Pfluger, P.; Krounbi, M. T.; Street, G. B. Phys. Rev.

$B$ 1983, 28, 2140.

(23) Waller, A. M.; Compton, R. G. J. Chem. Soc., Faraday Trans. 1989, 85, 977 .

(24) Bätz, P.; Schmeisser, D.; Göpel, W. Solid State Commun. 1990, 74,461 .

(25) Rapta, P.; Neudeck, A.; Petr, A.; Dunsch, L. J. Chem. Soc., Faraday Trans. 1998, 94, 3625.

(26) Santos, M. J. L.; Brolo, A. G.; Girotto, E. M. Electrochim. Acta 2007, 52, 6141

(27) Bally, T.; Nitsche, S.; Roth, K.; Haselbach, E. J. Am. Chem. Soc. 1984, 106, 3927

(28) Bally, T.; Roth, K.; Tang, W.; Schrock, R. R.; Knoll, K.; Park, L. Y. J. Am. Chem. Soc. 1992, 114, 2440.

(29) Smie, A.; Heinze, J. Angew. Chem., Int. Ed. 1997, 36, 363.

(30) Fichou, D.; Horowitz, G.; Xu, B.; Garnier, F. Synth. Met. 1990 , 39,243

(31) Fichou, D.; Horowitz, G.; Garnier, F. Synth. Met. 1990, 39, 125

(32) Evans, C. H.; Scaiano, J. C. J. Am. Chem. Soc. 1990, 112, 2694 41,463

(33) Fichou, D.; Xu, B.; Horowitz, G.; Garnier, F. Synth. Met. 1991,

(34) Caspar, J. V.; Ramamurthy, V.; Corbin, D. R. J. Am. Chem. Soc. 1991, 113, 600

(35) Zinger, B.; Mann, K. R.; Hill, M. G.; Miller, L. L. Chem. Mater. 1992, 4, 1113.

(36) Hill, M. G.; Penneau, J.-F.; Zinger, B.; Mann, K. R.; Miller, L. L. Chem. Mater. 1992, 4, 1106.

(37) Hill, M. G.; Mann, K. R.; Miller, L. L.; Penneau, J.-F. J. Am. Chem. Soc. 1992, 114, 2728.

(38) Guay, J.; Kasai, P.; Diaz, A.; Wu, R.; Tour, J. M.; Dao, L. H. Chem. Mater. 1992, 4, 1097.

(39) Guay, J.; Diaz, A.; Wu, R.; Tour, J. M.; Dao, L. H. Chem. Mater. 1992, 4, 254

(40) Wintgens, V.; Valat, P.; Garnier, F. J. Phys. Chem. 1994, 98, 228.

(41) Furukawa, Y. Synth. Met. 1995, 69, 629.

(42) Diaz, A. F.; Crowley, J.; Bargon, J.; Gardini, G. P.; Torrance, J. B. J. Electroanal. Chem. 1981, 121, 355.

(43) Pugh, S.; Bloor, D. Synth. Met. 1989, 28, 187.

(44) Groenendaal, L.; Peerlings, H. W. I.; van Dongen, J. L. J.; Havinga, E. E.; Vekemans, J. A. J. M.; Meijer, E. W. Macromolecules 1995, 28, 116

(45) Guyard, L.; Hapiot, P.; Neta, P. J. Phys. Chem. B 1997, 101, 5698

(46) Appel, G.; Schmeisser, D.; Bauer, J.; Bauer, M.; Egelhaf, H.-J.; Oelkrug, D. Synth. Met. 1999, 99, 69.

(47) Zotti, G.; Martina, S.; Wegner, G.; Schlüter, A.-D. Adv. Mater 1992, 4, 798 .

(48) Birnbaum, D.; Kohler, B. E. J. Chem. Phys. 1991, 95, 4783.

(49) Wenbo, E.; Ohkubo, K.; Sanchez-Garcia, D.; Zhang, M.; Sessler,

J. L.; Fukuzumi, S.; Kadish, K. M. J. Phys. Chem. B 2007, 111, 4320.

(50) van Haare, J. A. E. H.; Groenendaal, L.; Havinga, E. E.; Janssen,

R. A. J.; Meijer, E. W. Angew. Chem., Int. Ed. Engl. 1996, 35, 638.

(51) Sessler, J. L.; Aguilar, A.; Sanchez-Garcia, D.; Seidel, D.; Köhler,

T.; Arp, F.; Lynch, V. M. Org. Lett. 2005, 7, 1887.

(52) Street, G. B.; Clarke, T. C.; Krounbi, M.; Kanazawa, K.; Lee, V.;

Pfluger, P.; Scott, J. C.; Weiser, G. Mol. Cryst. Liq. Cryst. 1982, 83, 253.

(53) Appel, G.; Böhme, O.; Mikalo, R.; Schmeisser, D. Chem. Phys.

Lett. 1999, 313, 411

(54) Chakrabarti, S.; Das, B.; Banerji, P.; Banerjee, D.; Bhattacharya,

R. Phys. Rev. B 1999, 60, 7691.

(55) Zhou, M.; Heinze, J. Electrochim. Acta 1999, 44, 1733.

(56) Ford, W. K.; Duke, C. B.; Salaneck, W. R. J. Chem. Phys. 1982 77,5030 .

(57) Brédas, L.-L.; Silbey, R.; Boudreaux, D. S.; Chance, R. R. J. Am. Chem. Soc. 1983, 105, 6555.
(58) Brédas, J. L.; Thémans, B.; Fripiat, J. G.; André, J.-M.; Chance, R. R. Phys. Rev. B 1984, 29, 6761.

(59) Bakhshi, A. K.; Ladik, J.; Seel, M. Phys. Rev. B 1987, 35, 704.

(60) Pranata, J.; Grubbs, R. H.; Dougherty, A. J. Am. Chem. Soc. 1988, 110,3430 .

(61) Faulques, E.; Wallnofer, W.; Kuzmany, H. J. Chem. Phys. 1989, 90,7585

(62) Kofranek, M.; Kovar, T.; Karpfen, A.; Lischka, H. J. Chem. Phys. 1992, 96, 4464.

(63) Colle, R.; Curioni, A. J. Am. Chem. Soc. 1998, 120, 4832. 94,25

64) Millefiori, S.; Alparone, A. J. Chem. Soc., Faraday Trans. 1998,

(65) Colle, R.; Curioni, A. J. Phys. Chem. A 2000, 104, 8546

(66) Ma, J.; Li, S.; Liang, Y. Macromolecules 2002, 35, 1109.

(67) Tamm, T.; Tamm, J.; Karelson, M. Int. J. Quantum Chem. 2002, $88,296$.

(68) Tamm, T.; Tamm, J.; Karelson, M. Synth. Met. 2005, 149, 47.

(69) Casanovas, J.; Aleman, C. J. Phys. Chem. C 2007, 111, 4823.

(70) Zade, S. S.; Bendikov, M. Org. Lett. 2006, 8, 5243

(71) Salzner, U. J. Chem. Theor. Comput. 2007, 3, 219.

(72) Salzner, U. J. Chem. Theor. Comput. 2007, 3, 1143.

(73) Stevens, W. J.; Basch, H.; Krauss, M. J. Chem. Phys. 1984, 81, 6026

(74) Cai, Z.-L.; Sendt, K.; Reimers, J. R. J. Chem. Phys. 2002, 117, 5543.

(75) Dreuw, A.; Weisman, J. L.; Head-Gordon, M. J. Chem. Phys. 2003, 119, 2943.

(76) Parac, M.; Grimme, S. Chem. Phys. 2003, 292, 11.

(77) Salzner, U. Curr. Org. Chem. 2004, 8, 569.

(78) van Faassen, M.; de Boeji, P. L. J. Chem. Phys. 2004, 121, 10707.

(79) Dreuw, A.; Head-Gordon, M. Chem. Rev. 2005, 105, 4009

(80) Luo, Y.; Ruud, K.; Norman, P.; Jonsson, D.; Ågren, H. J. Phys.

Chem. B 1998, 102, 1710 .

(81) Hirata, S.; Head-Gordon, M. Chem. Phys. Lett. 1999, 302, 375.

(82) Hirata, S.; Lee, T. J ; Head-Gordon, M. J. Chem. Phys. 1999, 111, 8904.

(83) Salzner, U. J. Phys. Chem. A 2008, 112, 5458.

(84) Hehre, W. J.; Ditchfield, R.; Pople, J. A. J. Chem. Phys. 1972, 56,2257

(85) Dunning, J. T. H. J. Chem. Phys. 1989, 90, 1007. 327.

(86) Cossi, M.; Cammi, R.; Tomasi, J. Chem. Phys. Lett. 1996, 255,

(87) Frisch, M. J.; Trucks, G. W.; Schlegel, H. B.; Scuseria, G. E.; Robb, M. A.; Cheeseman, J. R.; Montgomery, J. A., Jr.; Vreven, T.; Kudin, K. N.; Burant, J. C.; Millam, J. M.; Iyengar, S. S.; Tomasi, J.; Barone, V.; Mennucci, B.; Cossi, M.; Scalmani, G.; Rega, N.; Petersson, G. A.; Nakatsuji, H.; Hada, M.; Ehara, M.; Toyota, K.; Fukuda, R.; Hasegawa, J.; Ishida, M.; Nakajima, T.; Honda, Y.; Kitao, O.; Nakai, H.; Klene, M.; Li, X.; Knox, J. E; Hratchian, H. P.; Cross, J. B.; Bakken, V.; Adamo, C.; Jaramillo, J.; Gomperts, R.; Stratmann, R. E.; Yazyev, O.; Austin, A. J.; Cammi, R.; Pomelli, C.; Ochterski, J. W.; Ayala, P. Y.; Morokuma, K.; Voth, G. A.; Salvador, P.; Dannenberg, J. J.; Zakrzewski, V. G.; Dapprich, S.; Daniels, A. D.; Strain, M. C.; Farkas, O.; Malick, D. K.; Rabuck, A. D.; Raghavachari, K.; Foresman, J. B.; Ortiz, J. V.; Cui, Q.; Baboul, A. G.; Clifford, S.; Cioslowski, J.; Stefanov, B. B.; Liu, G.; Liashenko, A.; Piskorz, P.; Komaromi, I.; Martin, R. L.; Fox, D. J.; Keith, T.; Al-Laham, M. A.; Peng, C. Y.; Nanayakkara, A.; Challacombe, M.; Gill, P. M. W.; Johnson, B.; Chen, W.; Wong, M. W.; Gonzales, C.; Pople, J. A. Gaussian 03, revision D. 01; Gaussian, Inc.: Wallingford, CT, 2004.

(88) Pariser, R. J. Chem. Phys. 1956, 24, 250.

(89) Rubio, M.; Ortí, E.; Pou-Amerigo, R.; Merchán, M. J. Phys. Chem. A 2001, 105, 9788 .

(90) Fesser, K.; Bishop, A. R.; Campbell, D. K. Phys. Rev. B 1983, 27, 4804 364.

(91) Raos, G.; Famulari, A.; Marcon, V. Chem. Phys. Lett. 2003, 379,

(92) Duarte, H. A.; dos Santos, D. A.; Rocha, W. R.; de Almeida, W. B. J. Chem. Phys. 2000, 113, 4206.

(93) Schreiber, M.; Silva-Junior, M. R.; Sauer, S. P. A.; Thiel, W. J. Chem. Phys. 2008, 128, 134110.

(94) Roos, B. O.; Malmquist, P.-A.; Molina, V.; Serrano-Andres, L.; Merchan, M. J. Chem. Phys. 2002, 116, 7526

(95) Christiansen, O.; Gauss, J.; Stanton, J. F.; Jorgensen, P. J. Chem. Phys. 1999, 111, 525 .

(96) Serrano-Andres, L.; Merchan, M.; Nebot-Gil, I.; Roos, B. O.; Fülscher, M. J. Am. Chem. Soc. 1993, 115, 6184.

(97) Serrano-Andrés, L.; Merchán, M.; Nebot-Gil, I.; Lindh, R.; Roos,

B. O. J. Chem. Phys. 1993, 98, 3151.

(98) Nishikawa, O.; Kato, H. J. Chem. Phys. 1986, 85, 6758.

(99) Zerbi, G.; Veronelli, M.; Martina, S.; Schluter, A. D.; Wegner, G. J. Chem. Phys. 1994, 100, 978.

(100) Plugh, S.; Bloor, D. Synth. Met. 1989, 28, C187. 
(101) Salzner, U. Conjugated Organic Polymers: From Bulk to Molecular Wire. In Handbook of Theoretical and Computational Nanotechnology; Rieth, M., Schommers, W., Eds.; ASP: Los Angeles, CA, 2006; Vol. 8; p 203.

(102) Zotti, G.; Schiavon, G. Chem. Mater. 1991, 3, 62.

(103) Fisher, A. J.; Hayes, W.; Wallace, D. S. J. Phys.: Condens. Matter 1989, $1,5567$.

(104) Shimoi, Y.; Abe, S. Phys. Rev. B 1994, 50, 14781.

(105) Tol, A. J. W. Synth. Met. 1995, 74, 95.

(106) Tol, A. J. W. Chem. Phys. 1996, $208,73$.

(107) Brocks, G. Synth. Met. 1999, 102, 914.

(108) Brocks, G. J. Chem. Phys. 2000, 112, 5353.
(109) Moro, G.; Scalmani, G.; Cosentino, U.; Pitea, D. Synth. Met. 2000, 108,165 .

(110) Gao, Y.; Liu, C.-G.; Jiang, Y.-S. J. Phys. Chem. A 2002, 106, 5380.

(111) Zade, S. S.; Bendikov, M. J. Phys. Chem. B 2006, 110, 15839.

(112) Zade, S. S.; Bendikov, M. J. Phys. Chem. C 2007, 111, 10662.

(113) Zamoshchik, N.; Salzner, U.; Bendikov, M. J. Phys. Chem. C 2008, 112,8408 .

(114) Champagne, B.; Spassova, M. Phys. Chem. Chem. Phys. 2004, 6, 3167.

JP8063257 